\title{
RELACIONES DE VECINDAD ENTRE ALBARRACÍN Y CUENCA. UNA APORTACIÓN A LA DIPLOMÁTICA MUNICIPAL ARAGONESA
}

Antonio Chacón.

Dentro del fondo de documentos bajomedievales custodiado en el Archivo Municipal de Cuenca hay un reducido número, seis en total, que tiene como emisor a su vecino el concejo de Albarracín. Todos ellos tratan asuntos más o menos directamente relacionados con el límite fronterizo que los separa,dándonos idéa de algunas cuestiones que preocupaban a los dos concejos, y que están referidas, fundamentalmente, al aprovechamientos de los buenos pastizales, así como a las decisiones administrativas tomadas en cada caso para no romper las amistosas relaciones de vecindad que han sabido mantener durante los años conflictivos del enfrentamiento bélico mantenido entre sus respectivos reyes, y que no deséan ver rotas en años de paz, por más que la situación fronteriza, preocupante siempre entre concejos por mantener la integridad de los territorios que administran, se vuelve especialmente delicada entre Albarracín y Cuenca, pues no sólo delimita sus términos municipales, sino distintos reinos.

\section{CONTEXTO HISTÓRICO}

El deseo de mantener íntegra su tierra fue tarea que preocupó desde el primer momento a las autoridades conquenses, y así lo refleja la disposición dictada, recogida en el Fuero ${ }^{(1)}$, mandando que los alcaldes y caballeros de la Sierra recorran sus términos para preservarlos de intromisiones no deseadas, a la vez que manda reponer los mojones que hayan sido destruídos y que marcaban los límites precisos. Pero en este proceso se encontrará con las mismas preocupaciones que los concejos colindantes, libres o de señorío, que inevitablemente le acarreará fricciones y enfrentamientos ${ }^{(2)}$.

El término de Cuenca estaba rodeado de tierras de señorío como el de Albornoz, de la Orden de Santiago y de la Mitra conquense, por otros concejos de realengo e incluso por el reino de Aragón a través de Albarracín, y con prácticamente todos ellos mantendrá relaciones no siempre de buena 
vecindad, sobre todo cuando la población fue en aumento y la tierra empezó a valorarse en todas sus posibilidades y no sólo con vistas a la explotacion de los pastos ${ }^{(3)}$. Hemos de pensar, por lo tanto, que la escasez de población y las limitadas parcelas dedicadas al cultivo hacía innecesarío llegar al extremo de enfrentar a dos comunidades vecinas por la propiedad de sus tierras, lo que vendría avalado por no encontrar documentado en el Archivo ningún litigio desde el final del siglo XII hasta bien entrado el siglo XIV.

Se dieron entonces dos géneros bien distintos de disputas territoriales, pues, ocurría que, mientras las diferencias con los concejos limítrofes solieron resolverse por avenencia, -conocedores los contendientes del riesgo político que suponía reclamar ante el tribunal regio-, en las lizas con los señores se hizo preciso, en cambio, acudir a la sentencia de un juez de términos, de nombramiento, real para llegar a un acuerdo ${ }^{(4)}$.

Sin excluir alguna esporádica roturación, inadecuada en principio con el esquema teórico de la crisis demográfica y agraria establecido para la época, por mera hipótesis, desde luego, hemos de atribuir a disputas por el uso de los pastos los duros debates que enfrentaron a los concejos de Alarcón y Cuenca en torno a 1350. Lindantes entre sí las aldeas de Gabaldón y la Motilla, pertenecientes al alfoz de Alarcón, con la del Campillo de Altobuey, sita en el sexmo de Altarejos de la Tierra de Cuenca, la falta de mojoneras claras entre sus términos había provocado que entre sus vecinos menudeasen las prendas e tomas e fuerças e feridas e robos e quebrantamientos de términos e logares ${ }^{(5)}$, cuando la ganadería requirió mayor superficie por haberse convertido en la actividad económica más adecuada a un tiempo en el que tantas adversidades de diverso signo se dieron cita. El nombramiento por parte de los concejos de ambas villas de ciertos vecinos provistos de poderes suficientes permitió finalmente restablecer, con los linderos, la concordia entre comunidades vecinas ${ }^{(6)}$.

$\mathrm{Si}$ bien es verdad que los enfrentamientos con la vecina ciudad de Abarracin los suscitaron siempre cuestiones de índole ganadera, el hecho de pertenecer a reinos distintos agudizaba de tiempo en tiempo estas elementales diferencias, cada vez que entre Aragón y Castilla se suscitaba una discordia. Asi sucedió en 1336, cuando a la muerte del rey aragonés Alfonso el Benigno (24-I-1336), doña Leonor, su viuda, hermana de Alfonso XI, hubo de refugiarse en Castilla con sus hijos Fernando y Juan huyendo de la sañuda persecución de Pedro IV, hijastro del difunto Alfonso IV. La contienda entre ambos reinos ${ }^{(7)}$ dió pie a don Juan Manuel para enemistarse del todo con su frustrado yerno Alfonso XI y desnaturarse de Castilla, poniéndose al servicio de Pedro IV, quien le autorizó a titularse duque de Villena, mientras Alfonso XI entregaba a don Pedro de Xérica, quien, como valedor suyo, había acompañado a la reina Leonor, el adelantamiento murciano. Las hostilidades duraron poco, sin embargo, en esta ocasión, debido a que el mayor interés ofrecido a ambos monarcas por la reconquista andaluza y el control marítimo del Mediterráneo, les aconsejó aproximarse hasta llegar a un acuerdo de colaboración, uno de cuyos preliminares tuvo lugar precisamente en Cuenca 
en 1338 con ocasión de la reconciliación entre el rey y don Juan Manuel aquí ratificada ${ }^{(8)}$.

Las consecuencias locales de cada guerra mayor eran siempre las mismas: muertes de labriegos y pastores, saqueos de ganados, destrucciones de cosechas, todo lo cual repercutía, como es natural, en un grave deterioro de las economías campesinas, especialmente árduo en estas áreas fronterizas. La habitual carencia de un mínimo sistema de intendencia obligaba a los ejércitos a vivir del pillaje y esto tornaba aún mayores los desastres bélicos, en la medida que además la contienda proporcionaba de ordinario una excelente coartada para la emergencia de la violencia señorial armada. Al comienzo de la llamada "Guerra de los dos Pedros" (I de Castilla y IV de Aragón), en los primeros días de agosto de 1356, cuando el infante Fernando, señor de Albarracín, decidía abandonar a su hermanastro el rey de Aragón para hacerse vasallo del monarca castellano, envió sendas cartas al concejo de aquella ciudad prohibiendo la saca de pan de ella y ordenando el castigo de quienes, amparados en la confusión del momento, hostigaban desde sus fortalezas al vecindario ${ }^{(9)}$.

No extrañará pues que, obligados a convivir día a día, cuando unos años más tarde renaciera la crisis bélica entre ambos reinos, optasen mejor por darse treguas particulares aquellos concejos serranos, tan perjudicados siempre en sus respectivas economías ganaderas por los hombres de armas de uno y otro lado de la frontera, cuya codicia hallaba pretexto en la guerra para saquear a sus vecinos, convirtiendo en batallas de ésta sus particulares operaciones de rapiña ${ }^{(10)}$.

Varios son los testimonios conservados de aquellos acuerdos. En 1364, al comienzo de la guerra dinástica en Castilla, cuando Pedro el Ceremonioso decidió prolongar la anterior querella sostenida contra su homónimo castellano prestando apoyo a la rebelión nobiliaria alzada contra este, a cuyo frente se puso el conde de Trastámara, su hermanastro, siempre con la ilusión puesta en trasladar la frontera aragonesa hacia el interior del obispado de Cuenca, autorizó, sin embargo, al concejo de Albarracín para pactar una tregua con el rey de Castilla, desde primero de noviembre de aquel año hasta igual fecha del siguiente ${ }^{(11)}$. Tres años más tarde, después de la derrota sufrida en Nájera frente a Pedro I y sus aliados ingleses ${ }^{(12)}$ por el rebelde don Enrique y su aliado Pedro IV, como preliminar de la tregua que ambos reyes firmarían en agosto, pactaron la suya Albarracín y Cuenca, entre el 23 de abril y la Navidad de $1367^{(13)}$. Y aún se renovaría por otro semestre en 1373, siete años después ${ }^{(14)}$, cuando Enrique II, ya convertido en rey de Castilla, prefirió continuar la guerra contra su antiguo aliado aragonés hasta 1375, antes que cumplirle las promesas, hechas en tiempos de apretura, consistentes en cederle, con Murcia, los bordes ibéricos del reino de Castilla, comprendida la porción oriental del obispado de Cuenca ${ }^{(15)}$.

Concluida la guerra, volverian de nuevo a primer plano los conflictos ocasionados por el uso de los pastos en el espacio serrano de Cuenca. Los 
había venido ocasionando, como se ha visto, la falta de claridad en los límites de los términos municipales, pero otras veces se trataba de hacer frente a la mera y simple usurpación de extensos espacios comunes, anejos a las heredades propias, en ocasiones sometidas ya al régimen señorial, realizada por los más poderosos ganaderos en detrimento de los intereses de la mayoria de labriegos, dueños también de pequeños hatos.

\section{ANÁLISIS DIPLOMÁTICO}

Para nadie es un secreto que el principio de procedencia puede constituir el pilar básico, a un tiempo conceptual e instrumental, sobre el que se ha de asentar la clasificación de cualquier conjunto documental, sin que importe la índole del trabajo que sobre él se pretenda realizar.

Quiere esto decir que sin plantear, siquiera someramente, las esferas de competencia gubernativa o administrativa, así como el funcionamiento de la institución de la que hayan emanado los documentos objeto de interés, resulta difícil proponer un esquema organizativo de los mismos, tanto si lo que se pretende es su simple clasificación y descripción archivística, como si, y éste es ahora el inmediato propósito, se trata de contemplar sobre todo los aspectos diplomáticos de la diferente tipología documental emanada de un municipio medieval aragonés.

No es éste lugar, ni la ocasión tampoco, de proponer el estudio institucional del concejo de Albarracín en los siglos bajomedievales, aunque en lo que toca a su actuación como órgano del poder local en las diferentes esferas de competencia que le estarían atribuidas en unos casos por la normativa foral y, en otros, por las disposiciones del derecho señorial y regio, su actuación no sería muy diferente de la protagonizada por otros concejos durante esos siglos medievales; por eso creemos que se pueden aplicar a este reducido conjunto documental los criterios seguidos para la estructuración del corpus municipal conquense elaborados en nuestra tesis doctoral ${ }^{(16)}$.

Alli decíamos que sin renunciar a cuanto de válido pueda tener el esquema de organigrama de la documentación municipal propuesto por el malogrado archivero del Ayuntamiento de Valladolid, Fernado Pino ${ }^{(17)}$, y sin dejar de reconocer el carácter pionero de su trabajo en este concreto espacio de la Diplomática, se había optado por organizar la documentación manejada con arreglo a otro sistema. Para ello nos dejamos guiar del principio de que cada documento testimonia de un apartado preciso de la actuación municipal ligada a las atribuciones que a las autoridades urbanas les estaban reconocidas.

En tanto que cada documento de los emanados por el concejo testimonia de las diferentes actuaciones realizadas y no todas ellas han tenido el mismo alcance ni han sido tampoco del mismo orden, en una primera clasificación se distinguirán fijándonos en los dos campos fundamentales de actuación municipal: Gubernativa y judicial. 
Con respecto a la actuación gubernativa, el concejo promulga en principio diferentes normas destinadas a regir en aspectos puntuales de la vida vecinal, las cuales tienen una expresión concreta a la vez que diversa, tanto por su contenido como por su forma y modo de emisión. En ocasiones la Asamblea toma determinados acuerdos circunscritos a señalar algunas características propias del ámbito de la vida administrativa y económica del concejo, que reciben el nombre de "ordenanzas"(18) y que, plasmados en en leyes obligan de modo permanente a los vecinos de la urbe. Sin embargo, los documentos donde por excelencia se contiene la gestión gubernativa de trámite ordinario del concejo, en forma de acuerdos, son las "actas" de sus sesiones, pues en ellas se recogen puntualmente las decisiones políticoadministrativas tocantes a aquellos asuntos que, de oficio, o a instancia de parte, dependían de su jurisdicción. Por regla general, su alcance gubernativo quedaba ceñido a la ciudad misma, pero no faltaban tampoco disposiciones que concernían igualmente a los vecinos de las aldeas que componian la tierra. De ninguno de estos tipos documentales tenemos en el Archivo conquense emanados del concejo de Albarracín

Ligadas directamente al trámite gubernativo se hallan las "cartas de poder". Desde el punto de vista diplomático, su actio no se limita a una simple comunicacón, sino que tiene también el caracter de ser un paso del procedimiento administrativo, dado que se emiten, designando un representante autorizado, para facilitar la realización de una determinada gestión de competencia exclusivamente concejil, encaminada a la conclusión de algún acto de gobierno.

La "carta abierta" y la "carta de solicitud de procuradores" han de se incluídas también en esta segunda categoría, pues apoyan igualmente un paso del trámite gubernativo, siquiera sea, como los ejemplos presentes, tomando contacto con una realidad conflictiva concreta, frente a la que cabía tomar algún tipo de decisión. En ambos casos se trata de comunicar al concejo conquense algunos asuntos conflictivos relacionados con la frontera entre los concejos que preocupan a los aragoneses, y paro cuyo desenlace amistoso se requiere el concurso de la buena voluntad del vecino castellano.

Las competencias administrativas que ejercía el concejo se encontraban ligadas a la gestión de su extenso patriminio territorial, la atención al fundamental problema de tener abastecida la ciudad de productos de consumo básicos 0 referidas a las cuestiones hacendísticas, bien encaminadas a la propia recaudación municipal o a la cobranza de los impuestos señoriales y regios. Otros aspectos puramente administrativos son los que atañen a los temas de la alta política municipal, y en este sentido ninguno tan importante como aquellos documentados en las dos "cartas de tregua", que afectan a las más directas relaciones entre ambos concejos, pues tratan de asuntos que tienen que ver con la guerra y la paz, no sólo entre simples concejos limítrofes, sino entre concejos sometidos a jurisdicciones reales distintas. Del mismo modo, la "carta de convenio" es muestra de la capacidad gubernativa en benefico de sus administrados, pues en ella el 
concejo de Albarracín llega a un acuedo con el de Cuenca para trazar la mojonera que separase los dos términos y, en consecuencia, la frontera que por este lado dividía los reinos de Castilla y Aragón. La jurisdicción contencioso-administrativa la ejercen las autoridades municipales, aplicando su propia normativa local para resolver litigios en los que se halla implicado el propio concejo, y, como parece lógico, no tenemos entre los documentos conquenses ninguno proveniente de Albarracín que recoja algún asunto relacionado con esta jurisdicción.

El otro gran cometido propio del ejercicio del poder municipal se refiere a sus atribuciones de carácter judicial, las cuales tenían lógicamente muy variada índole. Este poder judicial lo desempeñaba el concejo, mediante la designación de las personas que habían de componer el tribunal municipal. En él se sustanciaban los pleitos ordinarios en materia civil y criminal, articulándose, según sus respectivas vigencias, la particular normativa foral con lo prescrito por la legislación real. El testimonio definitivo y concluyente del ejercicio de este poder judicial serían las "sentencias", pero, obvio es decirlo, tampoco se conserva en el Archivo de Cuenca ningún documento de estas características. Cabía también que los particulares se sometiesen de modo voluntario a la autoridad de la justicia concejil, jurisdicción voluntaria, para que ésta ratificase algunos negocios o acuerdos privados de especial relieve, pero tampoco tenemos por qué guardar en Cuenca ningún documento que recoja uno de estos acto sustanciados por el concejo de Albarracín.

Aunque somos conscientes de las limitaciones que nos imponen el reducidísimo número de documentos aquí estudiado, teniendo en cuenta la doble vía competencial que asumen los concejos medievales y, en consecuencia, los documentos que generan como pruebas fehacientes de su actividad, considero oportuno proponer un organigrama que las vertebra y que puede servir como instrumento de trabajo válido y operativo a la hora de emprender el análisis diplomático de cualquier conjunto documental que haya surgido del quehacer cotidiano de una oficina municipal medieval. Ni qué decir tiene que el análsis de un fondo documental más nutrido y de más amplio horizonte cronológico habría aportado una variedad mayor en el abanico de especímenes documentales producidos por la escribanía municipal a instancia de los diferentes órganos concejiles de gobierno. Todo esto supone que el esquema propuesto es revisable y adaptable a otros supuestos documentales e incluso institucionales, y que son precisos aún muchos estudios referidos a depósitos archivísticos individualizados antes de poder llegar a establecer un organigrama de tipologías concejiles que pueda resultar convincente.

\section{CUADRO DE TIPOLOGÍA DOCUMENTAL MUNICIPAL}

\section{ACTUACIÓN DEL CONCEJO:}

\section{GUBERNATIVA:}

1- NORMATIVA:Ordenanzas 


\author{
2- DE TRÁMITE: Actas minicipales \\ Cartas de poder \\ Cartas misivas \\ 3- RESOLUTIVOS: ADIMISTRATIVOS: \\ Carta de avenencia \\ Carta de convenio \\ 4- CONTENCIOSO-ADMINISTRATIVO: \\ Apeo arbitral \\ Sentencia arbitral \\ II. JUDICIAL: \\ 1: - PLEITOS ORDINARIOS: \\ Sentencias de jueces \\ ordinarios(alcaldes) \\ 2- JURISDICCIÓN VOLUNTARIA.
}

\title{
NUESTROS DOCUMENTOS
}

Hecha la breve exposición del momento histórico que envuelve las relaciones de vecindad entre los concejos de Albarracín y Cuenca, inmersos en una guerra entre reinos que los condiciona y determina a la hora de emitir los documentos que analizaremos, y propuesto un viable organigrama de actuación concejil donde se gestan y a través de la cual se emiten, pasamos a enumerarlos para conocer el iter cronológico y el asunto concreto que los hizo llegar a Cuenca, así como la categoría diplomática que les atribuímos, no sin antes decir que estos documentos son fruto de las prerrogativas de gobierno, dentro de las actuaciones de trámite y de administración

Como ya se ha dicho, entre Cuenca y Albarracín hay un contencioso que durará varios años traspasando el ámbito puramente regional, pues se pretende trazar la frontera entre dos reinos. En abril de 1367 se tiene la primera noticia de la relación entre ambos concejos al emitir el de Albarracín una "carta de tregua" por tiempo limitado, desde oy que aquesta carta se faze fasta el día de Pascua de Navidat, durante el cual dicho concejo se compromete a no hacer guerra, mal ni daño al conquense, ni consentir que nadie se lo haga desde su territorio ${ }^{(19)}$. Es una tregua concejil de suma importancia, pues supone la autonomía de ambos concejos para tratar por su cuenta asuntos de interés común sin intervención de sus respectivos reyes, en unos momentos muy delicados para ambos reinos, ya que están peleando castellanos y aragoneses en la llamada "guerra de los Pedros", y apenas veinte días antes de hacerse este pacto ha tenido lugar la batalla de Nájera con la victoria de Pedro I y su reposición en el trono de Castilla, lo que ha supuesto la huída del bastardo Enrique al reino de Aragón ${ }^{(20)}$. Las cosas, sin embargo, no tuvieron que cambiar mucho, pues no habrán transcurriodo seis años antes de que se vuelva a emitir otra carta por el concejo de Albarracín al conquense, reiterándole las garantias de buena vecindad en una carta que 
repite, casí al pié de la letra, la misma estructura interna ${ }^{(21)}$. Ambos diplomas podrían ser calificados como "Cartas de hermandad"(22) hechas entre poblaciones vecinas para salvaguardar la seguridad de sus territorios en época de inestabilidad política ${ }^{(23)}$, pero lo mismo que la primera se autocalifica de carta de tregua, la siguiente lo hace con un calificativo más amplio y explícito como carta de tregua et segurança en la notificación, y como carta de tregua et hermandat en la suscripción puesta por el escribano; sin embargo, creo más oportuno denominarlas diplomáticamente como "cartas de tregua", pues ésta es en realidad su actio : una "tregua" por tiempo limitado durante la cual Albarracín no hará nada en perjuicio de su vecino el concejo conquense ni de sus habitantes.

Diez años despues de la primera relación epistolar y cuando han transcurrido tres de la repeticion de las treguas vecinales que en aquella se proponían, es decir, en 1376, para determinarlos límites entre Cuenca y Albarracín, y así poner fin a las contiendas por los pastos que había entre los hombres de ambos concejos, el de Cuenca solicitó de Enrique II poder nombrar procuradores para este negocio, pues se ve incapacitado para hacerlo por su cuenta al tratarse de departimiento e exterminamiento de los reinos, aunque el rey, confiando en el buen criterio de las autoridades concejiles, descansó en ellas la responsabilidad de escoger dos de sus vecinos, aquellos que estimasen más oportunos ${ }^{(24)}$. No parece, sin embargo, muy urgente para los de Albarracín solucionar esta cuestión, pues únicamente en juniode 1380 se deciden a nombrar los procuradores que se avendrán con los de Cuenca a señalar por dónde han de ir los mojones partideros de sus respectivos términos y reinos ${ }^{(25)}$, recibiéndose entonces en el concejo de Cuenca un documento que se autocalifica como carta de poder. La reunión para fijar la frontera que separaba los dos reinos tendrá lugar inmediatamente y de ella saldrá un acuerdo refrendado por los yunteros de ambos concejos en un documento que podemos calificar como "carta de convenio". En ella, los procuradores, interesados más por la posibilidad del beneficio de los buenos pastizales que la zona limítrofe encierra que de la fijación de la frontera, haciendo gala de un admirable sentido práctico conciertan la explotación común del terreno en discordia, acordando que los ganados mayores y menores de ambos concejos puedan pacer y beber las aguas en él sin temor a ser prendados, ni por los caballeros de la sierra ni por los caballeros montaraces que guardan los términos de las dichas ciudades, dejando la espinosa cuestión de la propiedad para otra ocasión ${ }^{(26)}$.

Como ya perecían intuir los propios junteros, la concordia no solucionó los problemas, puesto que en 1392 el concejo de Albarracín, mediante una "carta abierta", reclama al de Cuenca unas cabezas de ganados apresadas por sus caballeros de la Sierra ${ }^{(27)}$. Somos conscientes de que la denominación diplomática dada a esta carta nos sugiere inmediatamente el documento emitido por la Cancillería real castellana, redactado sobre pergamino y autenticado con el sello de cera pendiente, cuyos últimos ejemplares no parecen prolongarse más allá del reinado de Alfonso $\mathrm{XI}^{(28)}$; sin embargo, el 
documento emitido por el concejo de Albarracín en nada se parece a sus homónimos reales castellanos; por lo tanto se ha de desechar la idea de cualquier parentesco entre ambas. No obstante, esta denominación sirve para cartas otorgadas por concejos castellanos, en las que se encuentran verdaderas semejanzas tanto en el especto externo como interno, y en las que su igual denominación está plenamente justificada ${ }^{(29)}$. El motivo de mantener para esta carta de Albarracín una denominación que en principio puede parecer equívoca, es simplemente por coherencia con la propia oficina expedidora que la califica como carta abierta cuando anuncia los medios puestos para dar validez a lo actuado, aunque ciertamente el tono general del escrito, tanto en su formulación estructural como en su lenguaje, y lo mismo en sus caracteres externos, es muy propio de las cartas concejiles que siguiendo ejemplos reales castellanos se las denomina con el nombre en Diplomática común de "misivas".

Todavía en 1413 siguen los mismos conflictos por el aprovechamiento de los pastizales que la imprecisión en las fronteras provoca, y que obliga a las autoridades de Albarracín a recordar a las de Cuenca las cuestiones y debates ocurridas con frecuencia entre sus vecinos por prendas et reprendas fechas en los annyos et tienpos pasados, por no tener un justo conocimiento de los vedamientos, insistiéndole a nombrar procuradores que junto con los suyos traten de dirimir estas cuestiones aún pendientes ${ }^{(30)}$. Se ha dado precisamente la denominación de "carta de solicitud de procuradores" a este documento emitido por el concejo de Albarracín, atendiendo a que éste es precisamente el motivo de su actio expresado claramente en la parte dispositiva ${ }^{(31)}$. Por otra parte, tiene una estructura interna que presenta ciertas semejanzas con la "carta abierta" a la que acabamos de hacer mención, aunque en ésta se echa en falta el anuncio y la propia validación que rompe la total afinidad diplomática entre ambas. Pero, al igual que pasaba con aquella, su estructura y lenguaje está en consonancia con las "cartas misivas" castellanas.

\section{CARACTERES EXTERNOS}

Hagamos ahora referencia de la materia escriptoria y demás caracteres externos mediante unos breves apuntes que nos permitirán acercarnos, ya sabemos que de forma superfical porque el material disponible es escaso, a un aspecto de la cultura medieval poco considerado aún por buena parte de los estudiosos de esta época, como son los medios materiales y la forma en que los emplean y preparan en la cotidianidad de sus funciones los que tabajan en una oficina municipal de una pequeña ciudad, como es el caso de Albarracín.

Como soporte gráfico se eligió el pergamino en dos de los documentos enviados a Cuenca, ciertamente en aquellos que escrituran actos de gobierno municipal considerados de gran importancia política, como son las "cartas de tregua", a las que, sin duda, se las quiere dotar de prestancia 
externa en un momento donde el papel ya se considera como el soporte de uso nomal, aunque en honor a la verdad se ha de decir que es un pergamino poco flexible y de calidad deficiente, coincidiendo en la poca preparación que se les hizo para recibir la escritura, la cual se graba por el lado de la carne. Ambos son de formato horizontal y amplias dimensiones, si bién el primero es casi tres veces más largo que alto, y con holgadas plicas donde se perforaron dos orificios en aposición horizontal, de donde penden restos de cintas de colores variados (blanco, amarillo, marrón y sepia en el primero, cambiando el marrón por el azul en el segundo) que servían de lemniscos a los desaparecidos sellos concejiles.

Para redactar los otro cuatro documentos se eligió un papel de buena calidad, color blanquecino que el paso del tiempo ha dado un tono de marfil viejo, el cual parece salido del mismo molino pues, además de su hechura, el cedazo que forman los corondeles y puntizones es idéntico en todos ellos. Los puntizones son gruesos y bien visibles al trasluz, ocupando una media de entre $6 / 7$ cada $20 \mathrm{~mm}$., mientas que los corondeles se separan en torno a los 50 $\mathrm{mm}$. cada uno. Sólo en uno de ellos ${ }^{(32)}$ se observa la marca de papel puesta por el fabricante, aunque podemos pensar que los otros tres también la tuvieron, quizá incluso igual, y que ha quedado en la parte del pliego cortada para escriturar otro negocio ya que las dimensiones de los que han llegado a Cuenca son relativamente pequeñas para que formasen una sola hoja. La filigrana se sitúa al final del pliego, entre dos puntizones, y representa un cuerno de caza terminado en punta, sin asa. Al parecer es una marca que no se localiza en España, sino que procede del norte de Italia, aunque no hemos encontrado ninguna exactamente igual entre los ejemplares recogidos por Briquet ${ }^{(33)}$, ni por Vals ${ }^{(34)}$. Creemos interesante destacar que, ya en la temprana fecha de 1380, los comerciantes italianos hayan introducido en estas zonas montañosas del interior peninsular el papel producido en los molinos de la región del véneto, quizá de Fabriano, ya que según opina Vals no será hasta principios del siglo XV cuando el papel nacional empiece a quedar relegado por el italiano en las ciudades del centro peninsular, hasta llegar a cosumirse en las más sencillas oficinas notariales ${ }^{(35)}$.

En la preparación de la página que ha de recibir la escritura apenas se observa ningún esmero, lo mismo en uno que en otro material. Sin embargo, al contrario de lo que sucede en el pergamino, que el amanuense llena de escritura practicamente toda la superficio disponible, en el papel la caja gráfica está enmarcada por amplios márgenes, aunque, eso si, en uno y otro material la unidad de pautado es generosa $(6-7 \mathrm{~mm}$.). No se observa en ninguno de ellos el regleteo que condujo al escriba en su tarea para no torcerse, ni en el pergamino la línea de piques que serviría para trazarlo. Tampoco se han preocupad de introducir una mínima estética en los documentos, pues a penas las letras capitales destacan por su mayor módulo, ya que están ejecutadas con la misma tinta color ocre desvaído del resto textual. 
Ya hemos indicado la desaparición de los sellos pendientes que portarían los documentos en pergamino, mientras que de los emitidos en papel, únicamente la "carta abierta" lleva este signo validaticio del concejo. Como es propio de la materia donde se inserta, es de placa y se sitúa en la parte inferior del dorso, ligeramente hacia la izquierda y cubierto con una oblea que se conserva en pésimas condiciones, hasta el punto de hacerse imposible contemplar la representación de la impronta y de la leyenda, pudiendo solamente decir que su tamaño es de $60 \mathrm{~mm}$ de diámetro ${ }^{(36)}$. Junto al sello hay una rúbrica que bien pudiera ser la del encargado del registro municipal, pues, aunque es prácticamente indescifrable, hay ciertos rasgos que permiten intuir la constatación de Registrada.

Como caractéristica externa del quehacer notarial, además de emplear una tinta más oscura a la del tenor, podemos destacar el hecho de que sitúan su signo hacia el centro de la página, iniciándolo con una linea recta desde el margen izquiedo y, una vez ejecutado, vuelve a prolongar la línea hasta el derecho, lo mismo que cubren el renglón final, para evitar interpolaciones, con trazos muy personales. Y quizá se pueda pensar, como opinaba Martín, que sean tan confirmativos y originales como los propios signos, hasta el punto de que pueden ser suficientes para atribuir un documento a un notario determinado, localizándole cronológica y geograficamente ${ }^{(37)}$. 


\section{NOTAS DE PALEOGRAFÍA}

La unidad gráfica que se había conseguido en la Península durante los siglos XII y primera mitad del XIII se romperá en la segunda mitad de esta centuria, cuando se imponga el cursivismo gótico, surgiendo entonces distintas variedades gráficas de un tronco común ${ }^{(38)}$ que desarrollarán aspectos distintos en cada uno de los reinos peninsulares, según sean las influencias recibidas, y que Usón Sesé, en su lejana "lección", ya señaló ser francesas para el reino de Aragón ${ }^{(39)}$. Los seis documentos que estamos analizando fueron escritos entre las últimas décadas del siglo XIV y primeros años del XV, una época marcada por la cada vez mayor conexión con la cultura francesa, incluso desde antes que Juan $\mathrm{I}^{(40)}$ contrajera matrimonios sucesivos con dos princesas galas, sin olvidar la llegada a la corte aragonesa de los libros de la curia papal de Avignon ${ }^{(41)}$.

La letra de nuestros documentos se enmarca dentro de las características del cursivismo gótico que en esta parte de la Península se ha hecho común denominar con el sobrenombre de "aragonés"(42), ciertamente que influenciada por la bastarda francesa pues adopta las peculiares formas ahuesada de los caidos de la $f, p, q$ y $s$, y ya con una hechura gráfica que se identifica perfectamente con el bloque documental que Mateu lbars engloba dentro del prehumanismo trecentista ${ }^{(43)}$, y Millares denomina como "tipo B": "Letra gótica, de aspecto librario, de trazado regular y perpendicular a la línea de renglón, con renuncia a los trazos dobles de $f, s$ y a la forma tan peculiar de la $g$, y con alternancia de $d$ uncial con la cursiva"(44). De esta generalidad se sale la carta en la que se solicitan procuradores, pues, a pesar ser la más moderna en el tiempo, produce la impresión de haber sido copiada por un escriba que aprendió su profesión en época anterior, ya que emplea una grafía de trazos cursivos y arcaizantes caidos dobles en algunas letras. Por otra parte son dignos de mención, en todos ellos, los astiles alzados de $b, l$ y $h$ que forman un ojo muy abierto hacia la derecha y con inercia a volver al punto de origen, así como el peculiar primer trazo de la $v$ bastarda. Todos los documentos se vierten en romance, con giros y construcciones del dialecto aragonés y en una escritura en general clara, donde el amplio pautado refuerza la grata sensación de sultura.

El sistema abraviativo es básicamente igual que en Castilla: No se usa el punto como signo abreviativo, pero aparece después de palabra abreviada por contracción un trazo inclinado que en ocasiones puede desempeñar el papel de pausa breve. Como signo general se utiliza la línea horizontal, que señala qualquier clase de abreviatura, aunque la más frecuente sea elisión de nasales al final o en medio de palabra e incluso ausencia de una sílaba. Con mucha frecuencia indica elisión de $e$ intermedia o final, así como de $h$ en el compuesto $c h$. No se emplea apenas en unión de q para formar que, aunque sí cuando forma parte de una palabra para señalar ausencia de ve. La línea se combina con $p$ para formar los mismos signos taquigráficos que vemos en la letra castellana (ausencia de ero ar). 
Utiliza normalmente el signo tironiano para la conjunción et, aunque no sea dificil que ésta se ponga con letras y, lo que ya no es corriente en Castilla, hemos visto emplear en no pocas ocasiones el signo de con al principio de palabra sentado sobre la línea de renglón. Para abreviar er al final o dentro de palabra, o para indicar simplemente que falta $r$ fianal, se recurre a una vírgula de curva muy abierta que acaba cerrándose, mientras que no se ha usado el de $u r$, de excaso empleo también en Castilla

Como rasgo distintivo se puede señalar la forma de escribir la preposición de mediante una $d$ uncial, que una vez ha descrito su bucle, vuelve hacia el punto de origen, para prolongarse con inclinación ascendente a la derecha, en forma de pronunciada lengüeta.

Las letras sobrepuestas son escasas, usándose $i, 0 \mathrm{y}$, sobre todo la a, muy abierta, en forma de omega sin lineta.

Por otra parte, se ha de señalar que en el método de trabajo de los amanuenses no entra ligar las letras con curvas contrapuestas, y los nexos son los normales de letras que se unen por la prolongación de sus trazos. E] nexo st se produce porque es el bastón de la $s$ larga el que desciende para buscar la $t$, que sigue siendo baja, aunque esta caída sea algo normal en la $s$, pues tiene propensión a unirse con todas las letras que le siguen.

\section{ESTRUCTURA INTERNA}

1. Documentos gubernativos.

1.1. De Trámite.

1.1.1. Carta de poder.

Su inicio es el característico de los documentos tipo "acta", pues aporta, en primer lugar, los normales elementos cronológicos empezando por Anno.... La fórmula que indica el estilo se escribe en latín y en términos usuales en el siglo XIV, y en el mismo idioma se expresan los millares, mientras que las centenas y decenas se reflejan en números romanos, volviendo de nuevo a la forma literal, aunque ahora en romance, para señalar el día de la semana y, de nuevo, a las cifras romanas para consiganar el día del mes, precedidas de andados como aún prevalece en Aragón. Una vez informados del cuándo se indica el elemento tópico, según la exprsión normal que en Castilla abre las datas: en la ciudat....

La intitulación se inserta a renglón seguido, en un primer momento de forma institucional, sin olvidar el modo de ser convocados y el lugar concreto donde se reunirá la asamblea, así como la autoridad superior de quien ha partido la orden de su convocatoria, que en este caso actúa por delegación del que verdaderamente puede reunir el concejo. De ambos se da la filiación, precedida del título honrado y seguida de sus respectivos cargos. También se dan los datos del corredor público que ha ejecutado la orden del superior. A continuación se constituye la asamblea formalmente con las autoridades que acuden a la llamada, de quienes se dan los nombres 
completos además del topónimo y cargo desempeñado, cerrando el elenco de asistentes con la fórmula et des muchos homes buenos, los quales al dicho Concejo venir quisieron, que convierte la reunión en pública, cerrando esta parte con las consabidas fórmulas de concordia y unanimidad de criterio sobre lo tratado.Fuera de lo que hemos denominado intitulación formal, se constata la presencia de un delegado regio, pues no podemos olvidar que los procuradores tratarán asuntos que afectan a los interes del reino, por cuanto intervendrán en el trazado de la frontera con Castilla.

Después se pasa al cuerpo documental, consignando directamente el objeto del mismo. Así, el dispositivo se configura en torno a dos grupos de palabras. En primer lugar se ponen aquellas que lo definen y estructuran, a la vez que son una aseveración de la capacidad decisoria del Concejo, expresada en una cadencia tautológica no carente de sentido: Fazamos, establecemos, ordenamos.... En segundo lugar se ponen las cualidades de los procuradores, no subjetivamente, sino desde el punto de vista objetivo, es decir de aquellas virtualidades que les concede la persona que los establece y ordena como tales procuradores, y que ahora se explicta de forma genérica: ciertos, buenos et leales procuradores nuestros, de nos el dicho Concejo....

A renglón seguido se dan los datos que identifican a los investidos con la delegación, lo que podemos considerar como la dirección del documento. Esta parte se introduce con una formúla de cortesía formada con la preposición y el pronombre más el calificativo de dignidad usado normalmente por la escribanía del Concejo, a vos honrados, seguida de la filiación completa y el cargo desempeñado, más aquellas precisiones consideradas oportunas para evitar posibles irregularidades en el contenido del dispositivo, tales como si están o no presentes los designados en el momento de la actio y que no hay jerarquización entre ellos.

Sin solución de continuidad sigue el contenido y alcance del poder, volviéndose a recalcar quiénes son los poderdantes en cuyo nombrte han de actuar, y extendiéndose en una serie de consideraciones y normas que los designados han de observar para salvaguardar los intereses de su representado. Esta parte central concluye con unas cláusulas de características corroborativas. En primer lugar se pone una cláusula obligativa, por la cual el concejo se compromete a respetar todo lo que sus apoderados realicen en el ejercicio y campo de su designación, aunque sin poner como garantía del compromiso el secuestro de los bienes concejiles, algo que es constante en este tipo de ducumentos emitidos por el vecino concejo de Cuenca ${ }^{(45)}$. La segunda es el anuncio de validación, que especifica la categoría diplomática del documento y el estar garantizado por un notario que ha presenciado toda la actio, indicando así ante quien se otorgó el poder.

El documento se cierra con una data referenciada a la que abría el tenor, aunque ahora con el incipit Fecha. Tras está alusión a la fecha se mencionan los espectadores que en su momento podrían testificar sobre lo actuado, dándose de ellos los datos normales y sin olvidar su vecindad 
La validación la pone un notario público que indica serlo por designación real, pudiendo por ello ejercer su oficio en todo el reino de Aragón $^{(46)}$. En la suscripción deja constancia de su presencia durante la tramitación del negocio documentado, recogiendo la iussio para escribirlo directamente del Concejo, lo que hace él en persona, y poniendo todos los requisitos legales para que la "carta de poder", a la que vuelve a calificar de tal, tenga utilidad pública.

\subsubsection{Carta abierta.}

La estructura de esta carta se inicia con un protocolo donde se expresa directamente su destinatario con una fórmula de cortesía semejante a la empleada por otros concejos del mismo área geográfica cuando se relacionan con instuticiones afines ${ }^{(47)}$ y que son una muestra de respeto y deferencia hacia sus iguales interlocutores, $A$ los honrados el concejo, cavalleros....Le sigue inmediatamente la intitulación del otorgante inicada por el pronombre Nos, con mención de la persona jurídica más las autoridades de que consta. El saludo cierra esta parte protocolaria que es toda una muestra de buenos modos y deseos de mantener una amistosa relación con el destinatario de la carta, a quien manifiestan su aprecio y cordialidad: vos embiamos mucho a saludar de la salut et honra que para nos querríamos. Sirve de enlace entre esta parte protocolaria y el núcleo documental una cláusula notificativa para interesar al destinatario sobre el asunto que ha mitivado el escrito, todo en el mismo estilo literario claramente conciliador.

Con esto nos introducimos en el texto, cuya primera parte justifica la disposición. De esta forma, en el expositivo se narran los hechos que han movido al Concejo a expresar cúal es su voluntad sobre el tema tratado, poniendo a su interlocutor al corriente de lo ocurrido, que avemos entendido que agora, el domingo más cerqua pasado, y, aunque concluye con una especie de disculpa, le hace ver que se ha tomado la justicia por su mano, lo que vulnera los acuerdos de buena vecindad habido entre ellos, et esto no va bien entre buenas hermandades, ya sea ponemos más culpa en nuestro vezino.

Es en la segunda parte del cuerpo documental donde se refleja la voluntad de remitente, ya que mediante una alocución consecutiva y el verbo que estructura esta parte esencial, nos percatamos de que la acción emanada del documento es un ruego hecho al destinatario para que se informe bien de lo ocurrido antes de tomar decisiones que puedan hacer peligrar las buenas relaciones existentes entre ellos: Porque vos rogamos que tengades por bien de aver verdadera información..., et nos sería conservada la buena hermandat et amigança que ha seído antiguamente et es entre vos et nos.

Concluye esta parte con una cláusula que anuncia la validación de que consta, el sello, aunque no el modo como éste se apone, lo que sin duda fue acordado en sesión municipal, a la vez que indica la categoría diplomática 
otorgada por la oficina concejil al documento emitido: Et desto vos embiamos esta nuestra carta abierta et seyellada con nuestro seyello.

Las fórmulas que cierran el tenor se reducen a situar la carta en el espacio y en el tiempo. La data tiene como incipit una referencia directa a la conscriptio, Scripta, seguida del elemento tópico precedido del título urbano. Los elementos crónicos aportan el día del mes, con cifras romanas, su nombre y el cómputo anual, según el estilo de la Navidad, empleando la clásica expresión latina y la manifestación del año corriente en letras, aunque introduciendo también numerales romanos, tal como veiamos en la carta anterior, y que es una forma habitual de datar en esta zona peninsular ${ }^{(48)}$.

No lleva ninguna línea de validación, y únicamente está autenticada por el sello de placa del Concejo puesto al dorso, junto al que se observa una rúbrica indescifrable que, como ya apuntaba anteriormente, no creo responda a ningún nombre, sino que es la constatación de haberse anotado en el registro municipal antes de ser enviada a Cuenca.

\subsubsection{Carta de solicitud de procuradores.}

Al igual que lo hacia la carta anterior, ésta inicia su protocolo dirigiéndose al destinatario con una fórmula de cortesía en parecidos términos, aunque subyace un mayor grado de consideración y respeto. Así la dirección, después de un calificativo honorífico, menciona la institución destinataria de forma general, más las autoridades de que se compone, Muyt honorables concejo, cavaleros.... Le sigue la intitulación en la forma acostumbrada, precedida del pronombre Nos, para concluir con un saludo muy ritual: Salut et aparellada voluntat a vuestros plazeres.

Una locución notificativa hace de nexo de unión entre las fórmulas protocolarias y el texto, tratándose en este caso no de frases que alertan al destinatario, sino más bien de una reflexión surgida del propio remitente, Bien creyemos. Unida por la copulativa se pasa a dar la información que se considera oportuno sea conocida por el destinatario sobre el asunto que ha motivado la epístola, dando lugar a un expositivo que narra quejumbrosamente lo que viene sucediendo entre ambos concejos, dejándose entrever una actuación repudiable del conquense que aprovechó la circunstancia de que el reino de Aragón había estado algunos años sin rey, situación adversa que ha quedado resuelta con la coronación de Fernando de Antequera, y que anima a los de Albarracín a solicitar una reunión para zanjar definitivamente los enfrentamientos que se vienen arrastrando desde años pasados.

A la voluntad del concejo, que expresará claramente en el dispositivo, se accede mediante la locución consecutiva por aquesto, seguida de una fórmula de humildad, con aquella africción que mejor podemos, y haciendo al documento vehículo transmisor del deseo concejil, con las presentes, que expondrá mediante un verbo de súplica y una petición en demanda de justicia de tal forma hecha que hace pensar, al menos, en un 
reconocimiento tácito de inferioridad ante su interlocutor. A renglón seguido se hace la petición concreta, que es lo que ha motivado la emisión del documento: solicitar del concejo conquense el envío de procuradores para tratar de encauzar los conflictos y desavenencias que se viven entre los dos concejos, que pora conoscer et determinar todos et qualesquiere greuges contra aquesa ciudat et aquesta. Todo el dispositivo está redactado en un lenguaje literario que manifiesta gran deferencia hacia el destinatario, y bajo ese mismo sentimiento continúa una cláusula de ruego para que una vez aceptada su demanda se agilice la reunión de las partes: Et nos, esti concejo, asín vos lo rogamos et en debdo de justicia requerimos.

La cláusula de despedida pone fin al texto y en ella se invova la protección de la divinidad, en este caso de la Tercera Persona de la Trinidad, a la vez que se vuelve a insistir en que el concejo de Cuenca dé respuesta a su petición: El Santo Espiritu sea en vuestra guarda, et de lo que averdes enbiar ayamos vuestra respuesta.

Se cierra el tenor con los elementos cronológicos, que junto a la fórmula de despedida componen el protocolo final. El incipit de la data es idéntico al anterior, seguido del elemento tópico más los crónicos de día del mes, nombre de éste y año, donde se expresa el estilo en forma abreviada, usual desde el siglo $\mathrm{XV}^{(49)}$ a principio de cuya centuria se emite la carta comentada. Los elementos crónicos se reflejan según viene siendo normal jugando con las letras para componer cifras romanas, de esta forma se pone el día del mes, lo mismo que el año, aunque de éste sólo se haya indicado las centenas y decenas, obviando los millares, práctica habitual en Castilla en tipos documentales afines a éste y emitidos en su misma época ${ }^{(50)}$.

Nada hay externamente que valide la actio documental, pues carece de suscripción notarial y tampoco lleva firma de representante municipal alguno ni el sello del concejo que autenticaba el documento anterior desprovisto de otros elementos validadores, lo cual nos parece una irregularidad, pues todo documento, en principio, ha de llevar algún signo que garantice su autenticidad frente a la persona, sea ésta jurídica o particular, que la recibe. 


\subsection{Resolutivos.}

\subsubsection{Administrativos.}

\subsubsection{Cartas de tregua.}

Las dos cartas que hemos denominado de "tregua", aunque emitidas con unos años de diferencia tienen, sin embargo, una estructura interna muy parecida, incluso emplean fórmulas que se vierten en términos, literarios practicamente calcados, lo que hace pensar que se tuviera delante la primera cuando se redactó la segunda. No obstante, el tenor se abre de forma diferente, por cuanto aquélla se inicia con la clásica notificación general Sepan quantos, y ésta lo hace de forma más solemne con una invocación verbal dirigida a Dios . pero empleando términos tradicionalmente propios de Cristo y concluyendo con la partícula que reafirma lo antedicho, En el nombre de nuestro sennyor Dios. Amen.Continúa después con la clásica fórmula de notificación general que engloba la dirección y la calificación diplomática, carta de tregua et segurança, en sintonía con el negocio juridico que ha originado el documento.

Siguen ya las dos cartas igual, con la partícula como haciendo de enlace a una intitulación colectiva e iniciada con el consabido pronombre más referencia a la institución y a los cargos que la forman, el modo en que han sido convocados y el sitio concreto donde se reúnen, además de la unanimidad alcanzada en el contenido del dispositivo, todos concordes et bien avenidos a una voluntat et alguno nin algunos non contradicientes.

El núcleo documental lo compone el texto iniciado por un exposotivo donde se acumulan una serie de motivos que dan razón del porqué de la decisión concejil, $y$, aunque no deja de dar la impresión de ser un puro formulismo arropado de literátura espiritual, ciertamente se aducen motivaciones concretas y factibles, tales como preservar la buena amistad habida desde antiguo entre las dos ciudades y, al parecer, rota ahora por la gerra entre los reinos a que ambas pertenecen; por eso, el deseo latente en todo el expositivo es volver a la normalidad de buena amigança. Una vez expresadas las razones, mediante la locución por aquesto, que las asume, se entra de lleno en la parte central del documento, donde todo gira en torno a detallar las condiciones de la tregua.

En primer lugar, mediante una cláusula que salva la autoridad de su rey, atreviéndonos a la merçet del nuestro sennor el rey, se indica el objeto del acto del cual tienen conocimiento los otorgantes, según se expresa en las palabras definitorias que sirven de apertura al amplio dispositivo y que estructuran una fórmula cuyo lenguaje tiene reminiscencias feudales, donde parece que las disposiciones estipuladas responden a un acuerdo previamente pactado: otorgamos et reconosçemos que damos trehua buena, salva et sugura et verdadera, de dicho et de fecho et de consejo.

A continuación, se hace constar el beneficiario de la actio, que es el mismo destinatario del documento, a quien se nombra de forma institucional, precedido del pronombre a vos, como legítimo representante del término que gobierna y de las personas que lo pueblan. Después, se explicitan las 
obligaciones a observar por el concejo otorgante, concretadas en dos artículos y sus respectivas adiciones, incluyendo en la segunda carta un tercer artículo para recoger las contrapartidas que ha de observar el concejo conquense. Los artículos se inician por Primeramente, y los sucesivos por Otrosy, segidos de las palabras definitorias queremos et ordenamos, queremos et otorgamos. Las adiciones se hacen mediante la cución et si por aventura, con intención de concretar las responsabilidades contraídas si, por cualquier razón, se transgrediera lo dispuesto. La última adición se respalda con una cláusula de compromiso, saliendo el concejo de Albarracín garante de los posible daños que el incumplimiento de la tragua acarrease a la otra parte. El tercer articulo fija las contraprestaciones exigidas al concejo de Cuenca, aunque en realidad se trata de una sóla que parece preocupar al concejo aragonés, pues únicamente exige del castellano no dar cobijo, a sabiendas, a los que, causando daño en su término, crucen la frontera en busca de seguro refigio, hasta el punto de que utilizando una cláusula de características dispositivas, queremos et ordenamos, le otorga la capacidad de apresarlos e incluso de poder darles muerte.

Una serie de amplias cláusulas ponen fin al texto ${ }^{(51)}$ : La primera es de compromiso reforzada por otra conminatoria de pena de traición, mediante la cual el concejo de Albarracín se compromete por tiempo determinado, e incluso ampliable, a respetar lo dispuesto. La siguiente es de seguridad para los mercaderes conquenses que pasen la frontera, aunque no les exima del pago de los impuestos normales, ni les permita sacar del reino de Aragón las cosas vedadas, salvo los propios ganados que hayan entrado a pastar legalmente. La tercera es de corroboración que lleva aneja la concesión de un poder a dos de sus vecinos para que le representen a la hora de jurar la observancia de lo estipulado. Hay otra de juramento, donde se incluyen la filiación de los juramentados, quienes, en la fórmula del juramento, hablando subjetivamente dejan constancia de actuar por delegación de su concejo y ponen como testigo a la Virgen María, de cuyo señorío son vasallos los albarracitenses ${ }^{(52)}$.

En el anuncio de validación se expresa la persona jurídica de quien ha partido la iussio para que el documento sea redactado, con una nueva intitulación, a la vez que el material sustentate y los elementos que la validan. Por un lado, el signo concejil reflejado en el sello, del que se indica aposición $y$, por otro lado, el signo del escribano que será el transmisor verdaderamente eficaz de la fe pública quien, además, lo refrendará con su firma como testigo cualificado que ha sido de la actio documental.

En la data el incipit es Fecha seguido del topónimo, previo el título, y los elementos crónicos indican el día del mes y su nombre, más el año computado ya por la era cristiana, pues en el reino de Aragón fue abolida la hispana por Pedro $V$, en diciembre de $1349^{(53)}$, empleando la clásica expresión latina con los numerales en romanos, excepto las unidades que se desarrollan literalmente. 
La cita de testigos se introduce por una locución que deja clara su presencia durante el desarrollo del negocio jurídico documentado y, como es usual se dan los datos necesarios para su identificación, sin olvidar la vecindad.

Cierra el documento la suscripción de un notario público de Albarracín, quien emplea una fórmula iniciada por la copulativa $E t$, sin que falte ninguno de lo datos necesasrios de su persona y oficio, así como la indicación del lugar dónde esta capacitado para ejercerlo, según estipulaba la ley ${ }^{(54)}$. Después deja constancia de su presencia junto a los testigos en la sesión municipal donde se formalizó la actio, y reconoce haber recibido la iussio para su puesta por escrito del mismo concejo, lo que realizó él personalmente. Una vez dada la calificación del documento, concluye con la fórmula de aposición del sigo, donde indica haber seguido todos los requisitos marcados por la ley, como último signo validaticio llevaría el sello pendiente del concejo, actalmente perdido.

\subsubsection{Carta de convenio.}

De nuevo se ha elegido para redactar este convenio un documento tipo "acta", iniciándose, pues, con la fecha, que presenta la peculiaridad de una doble datación por tratarse de un convenio entre dos concejos pertenecientes a reinos distintos y con prácticas diferentes a la hora de reflejar el cómputo anual. En primer, lugar según la manera tradicional en Castilla, aunque omitiendo el elemento tópico, cosa muy rara entre los castellanos, se inicia directamente por el día de la semana más el del mes, contados por el estilo de andados, según fue norma entre los aragoneses ${ }^{(55)}$ y el nombre del mes, desarrollado todo literalmente. Enlazada por una locución que los equipara se da a continuacón el año, ahora según el estilo de la natividat, vigente ya desde hace tiempo en el reino de Aragón, y expresado un lengua latina mediante una fórmula usual en el siglo $\mathrm{XIV}^{(56)}$ con las centenas en numerales romanos. Los términos empleados y las expresiones lingüisticas son típicas de Aragón, resultando evidente que fueron los notarios de Albarracín quienes elaboraron y redactaron el documento-

La intitulación se compone de los intervinientes por ambas partes en el acuerdo, ante la presencia de sus respectivos fedatarios que serán los encargados de transmitir la utilidad pública y de unos testigos referenciados que solemnizarán la actio. Se menciona la comparecencia de las personas jurídicas a través de sus procuradores, que presentan los títulos que les capacitan para intervenir legitimamente en tal ocasión. La recepción y aceptación formal de estos apoderados se hace según el siguiente orden: Referencia de lugar, nombre de los procuradores, nombre del notario que les acompaña, concejo representado, delegación desempeñada y referencia de credenciales. Mediante una locución que indica la misma circunstancia, et semblantemente de la otra parte comparecieron en el dicho lugar, se pasa a registrar la comparecencia de la otra parte ( de Albarracín), empleando un esquema semejante. Se ha de señalar que en la presentación de 
procuradores de Albarracín no aparece constatado el notario que dará fe de lo ocurrido, sin duda por tratarse de la misma persona que está redactando el documento; también la costumbre de anteponer a los nombres el título de honrados y que, finalmente, al indicar la fecha de las cartas de procuración presentadas como credenciales, ésta se refleja según su propia normativa vigente, aunque en ambos casos señalando los días en números romanos, como se acostumbra en Aragón. El siguiente paso será la entrega de credenciales al notario de la parte contraria, como prueba y aval de su legal proceder.

Una vez cumplimentados estos requisitos burocráticos, se accede al texto inciado por un expositivo que consta de varios puntos:En primer lugar se hace una referencia general a la data tópica y crónica, mediante la expresión en este dicho día mismo et lugar, para referenciar posteriormente a las partes intervinientes con idéntica expresión, los dichos procuradores et yunteros, pasando después al motivo que los ha reunido, introducido por la expresión declararon en este fecho lo que sigue. El motivo de la junta se hace preceder de una nueva intitulación completa de las partes intervinientes, sin dejar de constatar que cada una de ellas ha examinado las credenciales de la otra para comprobar se legalidad. Por último, antes de pasar al dispositivo, se introduce una cláusula de salvedad del derecho de los respectivos reyes y ciudades involucradas, así como la motivación general del convenio a que se ha llegado: queriendo los servicios de los senyores reyes, así de Castiella como de Aragón, et el bien et provecho de las dichas ciudades... por tirar grandes questiones que fasta al día de oy se han recreçido entre las dichas ciudades et sus términos o se esperavan recrecer sobre los términos entredichos.

El dispositivo propiamente dicho es una concreción de las condiciones del convenio a que han llegado las partes, Se inicia mediante la locución por ende y consta de los siguientes puntos: Hay, en primer lugar, una especie de preámbulo para salvaguardar el derecho de las ciudades en cuyo nombre actúan los procuradores, sin olvidar que por encima de las cuestiones municipales hay involucrados derechos mas trascendentes que afectan a la frontera entre dos reinos y cuya fijación supera sus atribuciones. Después, se narran las razones que motivaron el convenio, para conclurir con una exposición de motivos que dará paso a la fórmula propiamente dispositiva, donde se reflejan las palabras que definen esta parte estructural tan amplia, previa una nueva referencia a las partes otorgantes y seguidas de la aseveración de actuar legítimamente, según las atribuciones que tienen concedidas: por nonbre de aquellas et por cada una dellas assentamos parte et avenencia por los dichos poderes en esta manera.Continúa el dispositivo con la explicitación del convenio, concretado en un artículo, con su adición, más una cláusula que entra en la gama de las reservativas pues deja bierta a instancias superiores la posibilidad de hacer las correcciones que estimen oportunas. Aún queda otra cláusula para concluir con el texto, la que indica haberse expedido dos originales dúplices, para que cada una de las partes 
implicadas tenga su ejemplar y lo pueda hacer valer, en el caso de que hubiera lugar a ello. La orden de redactar dos originales ha partido de los procuradores y va dirigida a sus notarios respectivo, a quienes mandan convertir el acuerdo privado en documetos públicos, refrendándolos con sus signos: Et sobre esto mandamos a los dichos notarios presentes que fagan dello dos cartas públicas, amas de un tenor, para cada una de las dichas cibdades la suya et las signen de sus signos.

El protocolo final cierra el tenor con convenio con las fórmulas que lo datan y lo validan. Su incipit es Fecha, pero teniendo en cuenta que los elementos crónicos ya se han puesto, pues con ellos se abría el documento. Ahora se añadirá el tópico, que es un sitio neutral, no un luagr urbano, sino rural donde se acordó el convenio y se tomaron las notas para la oportuna conscriptio. Después, se vuelve a repetir el día del mes, obviando todos los demás elementos crónicos con la partícula ut supra que remite a los aportados al principio.

Como primer elemento validatorio se citan los testigos de excepción que han contemplado el desarrollo del tratado, lo que es imprescindible para testimoniarlo. La segunda parte y principal de la validación la componen las suscripciones de los notarios desplazados por los concejos. Aunque falta el final del tenor, se puede, sin emabrgo, ver el inicio de la fórmula puesta por el escribano del conquense quien, como es de ley, refleja su nombre completo, profesión y lugar donde la ejerce, además de hacer constar su presencia junto a los testigos, entre los que se nombraría expresamente al notario actuante de la otra parte, tal como se hace en los documentos que recogen algún tipo de convenio. Sin duda, a continuación se vertería la suscripción del notario que transmite la fe pública en nombre del concejo de Albarracín. Lo que no podemos saber es sí, además del signo de cada notario, refrendarían el convenio con sus firmas o lo harian otros representantes concejiles, aunque según lo visto cuando analizamos documentos de similares características, entre Cuenca y otros concejos de su entorno ${ }^{(57)}$ se tendría que responder negativamente, pues ninguno está rubricado, pero no olvidemos que el tema del presente convenio no es un simple amojonamiento, sino el poder aprovechar comunalmente los pastos de un terreno que presenta dificultades a la hora de ser adjudicado a uno $u$ otro reino. 


\section{A MODO DE CONCLUSIÓN}

Las conclusiones que podríamos extraer de los documentos del concejo de Albarracín serían de gran utilidad, toda vez que los estudios de Diplomática municipal referidos a esta zona goegráfica integrada en el reino de Aragón son prácticamente desconocidos. Por ello, se ha de lamentar doblemente el reducidísimo número de los que hemos dispuesto para su análisis, ya que cualquier pretensión a este respecto no pasaría de lo puramente anecdótico; sin embargo, se pueden esbozar algunas consideraciones, sobre todo como fruto del cotejo con la documentación del concejo conquense, cuyo esquema organizativo ha servido para sistematizarla.

En primer lugar, estos documentos son fruto de las prerrogativas de gobierno, dentro de las actuaciones de trámite o de administración. Respecto a la diversidad de fórmulas empleadas no hay substanciales diferencias con las utilizadas por el concejo de Cuenca. De tipos dipomáticos encontramos los siquientes:

- Unos son de iniciación notificativa, que hemos denominado con el genérico de "carta", más lo específico de la naturaleza del acto.

- Por otra parte, han elegido el tipo "acta" en dos ocasiones para escriturar documentos de contenido dispar, siendo el más novedoso, respecto al conquense, una "carta de poder" que redactada de esta forma no responde a lo que es común en Castilla, aunque una vez expresados los elementos cronológicos retoma el esquema castellano.

- Utiliza también documentos de lenguaje coloquial y estructura epistolar que en Castilla se engloban bajo la denominación de "misivas", aunque se ha creído conveniente respetar en un caso la propia autocalificación de "carta abierta" y, en otro, atenerme exclusivamente a su contenido.

La referencia a un grupo de vecinos presentes en el desa rrollo del negocio escriturado es constante, a excepción de los dos últimos documentos a que acabo de referirme, asemejándose a las "misivas" castellanas también en esta ocasión. Otra diferencia se encuentra en el hecho de no formar parte del elenco testifical ningún escribano.

Donde se encuentra una mayor diferencia con la manera de hacer del concejo conquense es en la fórmula cronológica, pues si en éste la variedad estriba únicamente en el incipit, en razón de que se trate de un "acta" o de cualquier otro tipo, conservándose el resto estable, no sucede así en Albarracín, al variar los elementos de situación e incluso omitiendo el tópico de la fórmula amplia para reflejarlo en la data de referencia.

Los incipit pueden ser como en Castilla, Fecha, o totalmente diferentes, incluyendo el día de la semana, Llunes, o directamente el año, Anno, o haciendo referencia al momento de la conscriptio, Scripta, en las redactadas coloquialmente. Como sucedía en Cuenca, el día de la semana se refleja únicamente en los tipos "acta". Por otra parte aún se conservan arcaísmos dejados atrás en el modo de hacer conquense, como son el uso de los numerales prohibidos en Castilla por las Partidas (III, XIX, VII). En general, 
son las centenas las expresadas en cifras romanas y alguna vez las decenas y los millares, pero nunca las unidades, aunque se ha visto indicar así el día del mes en tres ocasiones, dos de las cuales son las redactadas en forma epistolar. La fórmula que emplea para indicar el año es siempre la misma, concisa y en latín, idioma nunca usado en Cuenca.

Como destacable en la cláusula de perfección es la diferencia en título adoptado, aquí de notario, mientras que en Cuenca siempre era el de escribano, pues por lo demás siguen las mismas pautas que los castellanos, ejerciendo el oficio públicamente sin estar sujetos a ningún cargo administrativo aunque, como allí, actúan por mandado del Concejo. Tampoco han firmado al pie de ningún documento, y los redactados e forma de "misivas" omiten cualquier tipo de suscripción notarial, pero en ocasiones se validan con el sello de placa al dorso. 


\section{NOTAS}

1. Fuero de Cuenca, edición crítica con introducción, notas y apéndice por R. UREÑA Y SMENJAUD. Madrid 1935, Apéndice I, p. 828

2. La existencia de conflictos enfrentando a concejos limítrofes por la defensa de sus respectivos términos, es más que frecuente en los tiempos medievales, puede servir como ejemplo los comentados por: J.A. MARTíN FUERTES, El concejo de Astorga. Siglos XIII-XVI. León 1987, pp.95-102.- F. PINO REBOLLEDO, El concejo de Valladolid en la Edad Media (1152-1399). Valladolid 1990, pp.23-24.

3. Cfr. J. TORRES FONTES, "Evolución del concejo de Murcia en la Edad Media", en Murgetana, LXXI (Murcia 1987) p.14

4. Debido al poder de los señores con los que se tiene que enfrentar, el concejo conquense solicitará del rey el envío de un corregidor capaz de enmendar los agravios que padece. El corregidor, durante todo el mes de agosto, acudirá personalmente a los distintos amojonamientos, acompañado de algunos procuradores nombrados por las partes interesadas para renovar los hitos y mojones partideros de términos que por ambas partes se habían derribado o removido de su original emplazamiento. Una vez en Cuenca dará sentencia definitiva fijando los límites jurisdiccionales que in situ se habian acordado (A.M.C. Leg. 34, exp. 1).

5. Archivo Municipal de Cuenca (A.M.C.) Leg.59, exp.1.

6. "Et visto todas las razones que sobre esto entre la una parte et la otra pasaron, avido nuestro consejo, sobre todo con onmes buenos sabidores, et tratada abenencia entre nos, por bien de paz, mandamos que así las pedras et tomas et robos et fuercas et feridas, commo quebrantamientos de términos et logares que son fechos entre los de Alarcón et del dicho Campiello en cualquier manera et por cualquier razón fasta oy, quesean nungunas et dámoslo todo por ninguno et por quitos a la una partarte et a la otra, assí commo si non fuesse fecho nin pasado alguna nin ninguna otra cossa de lo sobredicho o parte dello. Et mandamos, assí a los pendrados et robados et feridos, commo a los que fueron quebrantados términos et logares, en qualquier manera fasta oy, que todo lo haya por ninguno et non muevan unos a otros querellas nin pleitos nin demandas ante rey nin ante otro sennor nin ante judgado". ( 7 de diciembre de 1351. Avenencia hecha entre los yunteros de los concejos de Cuenca y Alarcón para amojonar los terminos de CampiIlo de Altobuey, Motilla y Gabaldón. A.M.C. Leg.59, exp.1.

7. El 20 de junio de 1336 Alfonso XI pedía a los concejos de la frontera aragonesa ayuda para que su hermana y el señor de Xérica conservasen sus castillos aragoneses, entre los que se encontraba el de Albarracín, cuyo señorío poseía el infante Fernando, hijo de Alfonso IV y Leonor. A.M.C. Leg. 8, exp. 3.

8. Gran crónica de Alfonso XI, Lib. VIII, cap. CCXLVIII, Ed. D. CATALÁN, Madrid 1977, II, pp. 248-249. 
9. “... fágovos saber que por los movimientos que son recrescidos entre los reyes de Castiella et de Aragón, por guarda de la dicha çibdat de Albarrazín et de su término, cumple mucho a mio serviçio et es mester que se ponga muy gran guarda en la saca del pan del dicho término". (Andújar, 3 de agosto de 1356) Archivo Municipal de Albarracín (A.M.B.), Colección documental, ff. 32 y 172.

Esta operación política era homóloga a la realizada en sentido opuesto por el conde Enrique de Trastámara, sellada luego en la concordia de Pina (9-XI-1356). Al declararse vasallo suyo, recibiría de Pedro IV el patrimonio aragonés del infante don Fernando. Cfr.J. ZURITA, Anales de la Corona de Aragón, lib. IX, cap. 5. Ed. A .CANELLAS LÓPEZ, Zaragoza 1973, vol. 4, pp. 306 y ss. ; Ibidem, IX, 6, p. 310.

10. Un ejemplo de aquel indiscriminado clima de violencia rapaz aún vivo en multitud de rencillas locales lo ofrece la siguiente provisión de Alfonso XI, dada para proteger a los vecinos de la villa episcopal de Pareja el 5 de noviembre de 1334: "Sepades que el concejo de Pareja se nos enbiaron querellare dizen que Bernabé Durche, alcayad del castiello de Trillo, que vino al término de este logar Pareja con otros conpanneros e que levaban ende robado pieça de ganado de sus veçinos, et que por esta razón que avíen de ir en pos ellos e que anparando el dicho ganado e non se queriendo dar a prisión, que remanesció y muerto el dicho Bernabé Durche; et agora el dicho conçejo dize que se temen que por la muerte del dicho Bernabé Durche que algunos omnes , sus parientes e otros algunos que querrán ir o pasar, sin razón e sin derecho, por esta razón contra algunos de sus vezinos que andan con sus mercadurías, .... A.M.C. Leg. 8, exp. 2.

11. "... que non contrastant que nos seamos et fagamos guerra contra el rey de Castella, nuestre enamigo, sines miedo nuestro et de nuestros oficiales a menos d'alguna nota d'infamia, podades fer treuga con el rey de Castella et sus gentes, del día de todos santos primero venidero a I anyo continuament subseguent." A.M.A. Colección documental, f. 36.

12. Cfr. A. GUTIERREZ DE VELASCO, "Los ingleses en España", en Estudios de la Edad Media de la Corona de Aragón, IV (1951) 215-319.

13. Los de Albarracín se comprometían a respetar las personas y bienes de todos los vecinos de Cuenca, a comunicarles con diez días de antelación la ruptura de la tregua en el caso de verse forzados a ello por el rey, y a perseguir y castigar a cuantos contraviniesen el pacto, tanto si los infractores fueran vecinos de su ciudad y aldeas, como si se tratase de algunos almogávares de otras partes del reino de Aragón. Doc. $\mathrm{n}^{\mathrm{a}} 1$.

14. La tregua pactada entonces, que estaría en vigor entre los últimos días de diciembre de 1373 y los del mes de mayo del año siguiente, fue adoptada sin contar con el previo acuerdo del rey aragonés, "... queriendo guardar servicio de Dios et de los senyores reyes et paz et concordia entre christianos, sennalladamente entre aquellos que antiguamente ovieron con nos buena amigança et buena hermandat, segunt que de aquesto tenemos cartas 
complidamente ante de agora fechas et otorgadas, et por evitar los males passados et que los buenos bivan en paz et en sonsiego et los malos ayan justicia et escarmiento, por aquesto, atreviéndonos a la merçet del nuestro senyor el rey, ..." . Doc. ํㅡㄴ. 2 .

Poco antes de que expirase, el infante don Juan, a la sazón gobernador por su padre, hacía saber a todos los súbditos del rey de Aragón que era "serviçio del sennor rey et nuestro que los ganados, assí grossos como menudos, de la ciudat de Santa María de Albarrazín et de sus términos, sean redrados de la frontera de Castiella et puestos dentro en el regno", por lo cual les ordenaba permitirles pastar en cualesquier términos de éste, siempre que no sufriesen daños de los animales evacuados. A.M.A. Colección documental, f. 5.

15. Cfr. ZURITA, Anales..., Lib. X, cap.10, ed. cit. Vol. 4, p. 606.

16. Cfr. F.A. CHACÓN, La documentación del Archivo Municipal de Cuenca. 1190-1417. Estudio diplomático e histórico institucional. Vol. II. Tesis doctoral leída en la Universidad Autónoma de Madrid en junio de 1993. Inédita. pp.623-632.

17. Cfr. F. PINO REBOLLEDO, Diplomática municipal. Reino de Castilla.14741520. Cuadernos de la Cátedra de Paleografía y Diplomática. VI. Valladolid 1972, pp. 15-17; Tipología de los documentos municipales (siglos XII-XVII). Valladolid 1991, pp. 22-23. Para este autor, atendiendo a su naturaleza los documentos emanados del Concejo pueden dividirse en: Constitutivos: Los que con fuerza jurídica crean un municipio donde no lo había o le dan refrendo legal cuando su existencia era anterior. De régimen interior: Los que regulan la vida, instituciones y diversos departamentos que componen el Concejo. De relación: Los expedidos por el municipio y que se dirigen a personas $u$ organismos extraños al mismo.

Esta misma clasificación han segudido: J.M. CUÑAT CISCAR, “ Diplomática municipal.Análisis y tipología de la documentación municipal valenciana a principios del siglo XIV", en Estudios, VIII (Valencia 1988. Separata de Saitabi, XXXVIII) pp.101-107.- A.J. LÓPEZ GUTIÉRREZ, "Documentación señorial y concejil del señorío de Cogolludo en el Archivo Ducal de Medinaceli (1176-1530)", en Historia. Instituciones. Documentos, 10 ( Sevilla 1984) pp. 195-208; Documentación del señorío de Cogolludo en el Archivo Ducal de Medinaceli de Sevilla (1176-1530). Zaragoza 1989, pp.120-130.- M.L.PARDO RODRÍGUEZ, Huelva y Gibraleón (1282-1495). Documentos para su historia. Huelva 1980, pp. 34-38.- E.C. DE SANTOS CANALEJO, "El Archivo Municipal de Piedrahíta: Tipología documental bajomedieval en una villa del duque de Alba y cabeza de una comunidad de villa y tierra", en Anuario de Estudios Medievales, 18 (1988) 14-18.- M. J. SANZ FUENTES, "Tipología documental de la Baja Edad Media castellana: documentación concejil. Un modelo andaluz: Écija", en Archivística. Estudios básicos. Sevilla 1981, pp. 199-207; "Diplomática real y concejil de la Corona de Castilla (1966-1991). Estado de la cuestión", en Historia. Instituciones. Documentos, 19 (1992) 454-457.-Para época posterior pues estudia docuemntos del siglo XVI, Carrilero ha estructurado la documentación municipal de acuerdo con el carácter general del nego- 
cio documentado: económico-hacendístico, administrativo, notarial, juducial. Cfr. R. CARRILERO MARTÍNEZ, "Diplomática municipal albacetense en la primera mitad del siglo XVI. Una aportación al estudio del documento privado castellano en los comienzos de la monarquía autoritaria", en Al-basit, 14 (1984) 65-87.

18. Cfr. J.M. PÉREZ-PRENDES, Curso de Historia del Derecho español. vol. I Madrid 1984, p. 653.- En el trabajo conjunto sobre las Ordenanzas municipales de Ladero y Galán se propone un esquema de ocho epígrafes donde tendrían cabida las distintas disposiciones concejiles dependiendo del asunto en ellas tratados: organización y funcionamiento del concejo; vecindario; bines de propios y fiscalidad concejil: marco de la vida urbana; política urbana; abastecimiento de la ciudad y sus condiciones; comercio y mercado urbano; actividad de los diversos oficios; economia agraria. Cfr. M.A. LADERO-J. GALÁN, "Las ordenanzas locales en la Corona de Castilla como fuente histórica y tema de investigación (siglos XIII-XVII)" en Anales de la Universidad de Alicante. Historia Medieval, Alicante 1982, pp. 240-243.

19. Doc. $\mathrm{n}^{\mathrm{o}} 1$.

20. Cfr. J. VALDEÓN, Enrique // de Castilla: la guerra civil y la consolidación del régimen (1366-1371), Valladolid 1966, pp.149 y ss.

21. Doc. $\mathrm{n}^{\circ}$ 2.- $\mathrm{Si}$, como cabría suponer, el concejo de Cuenca emitió cartas en contrapartida al concejo de Albarracin, estas, al parecer, no se han conservado en su archivo. Cfr. J. CARUANA Y GÓMEZ DE BARREDA, Catálogo del Archivo de la ciudad de Albarracín. Teruel 1974.

22. Puede verse a este respecto: M.J.SANZ FUENTES, "Cartas de hermandad concejil en Andalucía: el caso de Écija", en Historia. Instituciones. Documentos, 5 ( Sevilla 1978) 403-429, donde recoge publicaciones sobre hermandades realizadas en el ámbito de la Corona de Catilla. Desde el punto de vista meramente diplomático la misma autora ha tratado estos documentos en "Tipología documental de la Baja Edad Media Castellana: Documentación concejil. Un modelo andaluz:Écija." Archivística. Estudios básicos. Sevilla 1981, pp.201, donde los califica como documentos constitutivos de concejo. También Pino estudia algún documento de estas características y lo engloba dentro de los documentos de relación. Cfr. F. PINO REBOLLEDO, Tipología de los documentos municipales (siglos XII-XVII). Valladolid 1991, pp.66-71.

23. Cfr. L. SUÁREZ FERNÁNDEZ, "Evolución histórica de las hermandades castellanas", en Cuadernos de Historia de España, XVI (Buenos Aires 1951) 7.

24. A.M.C. Leg. 113, exp.1.

25. Doc. $n^{-} 2$.

26. Doc. $n^{\circ} 4$.

27. Doc. $\mathrm{n}^{\circ} 5$.

28. Aunque Floriano es de la opinión que este tipo documental no traspasó el reinado de Fernando IV, ya Millares lo desmintió al encontrar cartas de este tipo durante el reinado de su hijo Alfonso XI. También en mi Memoria de li- 
cenciatura analicé un documento que era un claro exponente de Carta abierta, emitida por la Cancillería del mencionado rey. Cfr. A. FLORIANO CUMBREÑO, Curso general de Paleografía y Paleografía y Diplomática españolas. Oviedo 1946, p.526.- A MILLARES CARLO, "Breves consideraciones sobre la documentación real castellanoleonesa en pergamino entre los siglos XIII y XV", en Estudios dedicados al profesor A. Marín Ocete, II, Granada 1974, p. 745.- A. CHACÓN, Colección documental del Archivo Municipal de Cuenca: Estudio paleográfico y diplomático.I. Memoria de licenciatura inédita, pp. 317-320.

29. Tal es el caso, por ejemplo, de algunos documentos analizados por F. PINO REBOLLEDO, Tipología de los documentos..., pp. 53-60.

30. Doc. $n^{\circ} 6$.

31. Para llevar a cabo una tipología que agrupase a los documentos emitidos por el "consell" de Valencia, Cuñat tiene en cuenta las características internas de dichos documentos, reuniendo bajo el calificativo de "procura" a los que designan representantes concejiles, que serían las "cartas de poder" o de "procuración" castellanas. Dentro de estos "procura" reserva un apartado para las "cartas de solicitud de procuradores". Al disponer entre nuestros documentos de uno solo cuya actio sea precisamente solicitar al vecino concejo conquense el envío de procuradores para tratar un asunto de interés común, no encontramos inconveniente en aceptar esta denominación propuesta por Cuñat que, además, está referida al mismo reino y cercana área freográfica que el conservado en el Archivo de Cuenca. Cfr. M.V. CUÑAT CISCAR, "Diplomática municipal. Análisis y tipología de la documentación municipal valenciana a principios del siglo XIV", en Estudios, VIII (Valencia 1988. Separata de la revista Saitabi XXXVIII) 105.

32. Doc. $n^{0} 3$.

33. Cfr. C.M. BRIQUET, Les filigranes, II. Leipzig 1923, pp.418 y ss. num. 7642 y ss.

34. Cfr. O. VALS I SUBIRÁ, La historia del papel en España. Siglos X-XIV.I. Madrid 1978, pp. 234 y 246, num. 26 y 27.

35. Ibidem, p. 229. A este respecto es muy interesante el estudio del trasiego comercial entre España y el norte de Italia realizado por Melis, y entre cuyo radio de acción se encontraba esta zona hispana. Cfr. F. MELIS, Mercaderes italianos en España (siglos XIV-XVI). Sevilla 1976, pp. 176-199.

36. Julio González, en su estudio sobre los sellos concejiles medievales no hace ninguna mención al que pudiera haber usado el concejo de Albarracín, y tampoco Guglieri cataloga sello alguno de este concejo. Cfr.J. GONZÁLES, "Los sellos concejiles de España en la Edad media", en Hispania V (1945) 339-385.- A. GUGLIERI NAVARRO, Catálogo de sellos de la Sección de Sigilografía del Archivo Histórico Nacional, III. Valencia 1974, pp.65-93.-Por otra parte ninguno de los documentos originales del Archivo de esta ciudad parece conservar el sello. Cfr. J. CARUANA GÓMEZ DE BARREDA, Catálogo..., pp. 21-24. 
37. Cfr. J.L.MARTÍN MARTíN, Documentos de los archivos catedralicio y diocesano de Salamanca (siglos XII-XIII). Salamanca 1977, pp.71-72.

38. Cfr. A MILLARES CARLO, Tratado de Paleografía española, I. Madrid 1983, p.109.

39. Cfr. M. USÓN SESÉ, Contribución al estudio de la cultura medieval aragonesa. La escritura en Aragón del siglo XI al XVI. Zaragoza 1940, p.19.

40. Los reyes de Aragón sienten una profunda atracción por su vecino reino del norte y en la cultura y moda francesa será educado Juan I. Cfr. A. CANELLAS - J. TRENCHS, "Cancillería y cultura. La cultura de los escribanos y notarios de la Corona de Aragón (1344-1479)", en Folia Stuttgartensia. Zaragoza 1988, sobre todo pp. 27-69.

41. Cfr. L. D'ARIENZO, "Alcune considerazioni sul passagio dalla scrittura gotica all umanistica nella produzione documentaria catalana dei secoli XIV e XV', en Studi de Paleografia e Diplomatica, Padova 1974, p.208

42. Pueden verse a este respecto una serie de trabajos que tratan desde diversos puntos de vista el momento gráfico de la Corona de Aragón en que se inscriben los documentos estudiados, y que no siempre están de acuerdo en denominar a la escritura de este reino como de "aragonesa". F.M. GIMENO BLAY, La escritura gótica en el país valenciano después de la conquista del siglo XIII. Valencia 1985, sobre todo pp. 83-111.- F.M. GIMENO -J.TRENCHS, "La escritura medieval de la Corona de Aragón (1137-1474)", en Anuario de Estudios Medievales, 21 (1991) 493-512. - L. D'ARIENZO, "Alcune considerazioni...", pp. 194-225.- F.C. CASULA, "Alcune note sulla letra aragonesa' del secolo XIV", en Annuali della Facoltá de Lettere, Filosofie e Magisterio dell'Universitá di Cagliari, XXX, 1967; Breve storia della scritura in Sardegna. La documentaria nell'epoca aragonesa. Cagliari 1978, sobre todo pp. 97 y ss.

43. Cfr. J. MATEU IBARS-M.D. MATEU IBARS, Colectanea paleográfica de la Corona de Aragón. Siglos IX-XVIII. I. Barcelona 1991, pp. 56-60-

44. Cfr. A. MILLARES CARLO, Tratado..., I. p. 239.

45. Así lo hemos constatado siempre en las "cartas de poder" emitidas por el concejo conquense y analizadas en nuestra tesis doctoral. Cfr. A. CHACÓN, La documentación..., II. pp.658 y ss.

46. Aunque Pedro II, en los Cortes de Monzón de 1362, había establecido la obligación que tenía cada notario de poner en su suscripción el lugar donde habitaba, aquellos que lo eran por designación real podían actuar en todo el territorio del reino, aunque con determinadas limitaciones y competencias, tal como también ocurría entre los escribanos de estas características en Castilla. Cfr. J.L. MERINO HERNÁNDEZ, "La institución del notariado en Aragón", en El patrimonio documental aragonés y la Historia, Zaragoza 1986, p. 144.Véase a este respecto la opinión coincidente de J. BONO HUERTA, Historia del Derecho Notarial español, I.2. Madrid 1982, pp. 175-178, donde da una opinión coincidente hablando de los notarios de creación real y las limitaciones que se ponían a sus competencias. 
47. Fórmulas iniciales semejantes dice Cuñat que emplea el "consell" de Valencia en sus constantes relaciones con otros "consells". Cfr. V.M. CUÑAT, "Diplomática municipal...", p 95.

48. Cfr. A. FLORIANO CUMBREÑO, Curso general de Paleografía y Paleografía y Diplomatica españolas. Oviedo 1946, pp. 311-313.

49. Cfr. A. FLORIANO CUMBREÑO, Curso general..., p. 313.

50. Cfr. Ibidem, p. 540

51. En la primera carta sólamente se ponía la claúsula de compromiso con la misma conminatoria de pena de traición, aunque sin concretar el tiempo de la tregua.

52. Cfr. J.F. RIVERA RECIO, "La erección del obispado de Albarracín", en Hispania 14 (1954) 34.

53. Las Cortes de Zaragoza de 1349, en su Fuero 5 De tabellionibus, dispuso que en lugar de la era, los natarios pongan anno a nativitate Domine. Citado por J.L. MERINO HERNÁNDEZ, "La institución del notariado...", p. 148 54. Pedro II en las Cortes de Monzón de 1362, había establecido la obligación de que cada notario pusiese en la suscripción el lugar donde tenía competencia para actuar como garante de la fe pública. Cfr. Ibidem, p. 144.- J. BONO HUERTA, Historia del Derecho..., I.2.pp.173-174; la legislación notarial la resume Bono en la obra citada, I.1. pp. 284-286.

55. Cfr. A. FLORIANO CUMBREÑO, Curso general..., p. 313.

56. Cfr. Ibidem, idem

57. Cfr. A. CHACÓN, La documentación..., Il. pp. 712-719. 


\section{APÉNDICE DOCUMENTAL}

1367, abril 23, Albarracín.

Carta de tregua por tiempo determinado entre los concejos de Albarracín y cuenca.

A.- A.M.C. Leg. 3, Exp. 9. Perg. de $260 \times 630 \mathrm{~mm}$. Plica de $25 \mathrm{~mm}$.con dos orificios en aposición horizontal y restos de cinta de lino en varios colores, de donde pendería el sello, hoy perdido. Escritura gótica cursiva aragonesa; tinta ocre; buena conservación.

Notas: En la plica, letra coetánea: "CCC LXXX". Notas de Archivo al dorso: Letra coetánea: "Scripturas (?) de tregua de Albarrazín e de Cuenca. 1367 annos". Letra del s. XVI: "Concordias entre Albarraçín e Cuenca". Letra del s. XVIII: "Tregua de la ciudad de Albarracín con esta de Cuenca. Copiado al folio 113 del Libro de Baqueta". "18". "Folio 113". "Número 18 (tachado)". "6으"

B.- Libro de Baqueta, fol. 113 r. - 114 r., (A.M.C. Leg. 17, Exp. 1).

EDT.: C.ROMERO DE LECEA, Privilegios reales, y viejos documentos. X. Cuenca. Joyas Bibliográficas. Madrid 1972, doc. $\mathrm{n}^{\circ}$.

CIT.: J.M. SÁNCHEZ BENITO, Las tierras de Cuenca y Huete en el siglo XIV. Historia económica. Universidad de Castilla la Mancha, 1994, pp. 25,70 .

Sepan quantos esta carta verán como nos, los offiçiales, conçejo et homes buenos de la çiudat de Santa María de Albarrazín, plegados en conçejo, clamado por boz de Johán de Frías, sayón público de la dicha çiudat, todos concordes et bien abenidos, queriendo guardar serviçio de Dios / et de los senyores et paz et concordia entre christianos, sennyaladament entre aquellos que antigament ovieron con nos buena amigança et buena hermandat, segunt que de aquesto tenemos cartas conplidament fechas et otorgadas, por aquesto, desde oy que aquesta carta se faze, fasta al / día de Pascua de Navidat de Nuestro Sennor Jeshu Christo, primera vinient, damos tregua buena, salva et segura de dicho et de fecho et de consejo, a vos, el conçejo, alcaldes, judez, cavalleros et escuderos et homes buenos de la çiudat de Cuenqua, et a los vezinos et havitadores en la dicha çiudat $\beta$ de Cuenqua et en sus términos, et a todo lo vuestro en esta maner:

Primeramente, que por nos, los ofiçiales, conçejo et homes buenos de la dicha çiudat de Santa María de Albarrazín nin por los vezinos nin havitantes en la dicha çiudat de Santa María de Albarrazín nin en sus términos non sea fecha guerra, mal, nin da-/nnyo a vos, el conçejo, alcaldes, judez, cavalleros, escuderos et homes buenos de la dicha çiudat de Cuenqua nin a los vezinos nin havitantes en la dicha çiudat de Cuenqua nin en sus térmi- 
nos, nin a cosa de lo vuestro, de dicho nin de fecho nin de consejo, por todo el dicho tienpo, nin consentiremos que vos sea fecha guerra, / mal, nin dannyo, a vos nin a cosa de lo vuestro.

(Calderón) Item, que si en el dicho tienpo acaesçiere que por mandado de rey o de sennyor, o de otro mayor o más poderoso que nos, oviésemos mandamiento, o nos forçasen que fiziésemos guerra contra vos, o que el dicho rey o sennor o mayor o poderoso quisiese fazer $/^{6}$ guerra desde la dicha çiudat o desde sus términos, que escusar non lo pudiésemos, contra a la dicha çiudat de Cuenqua o contra sus términos o contra alguna cosa de lo suyo, que nos, diez días antes, que seamos tenidos de fazerlo saber por carta nuestra, o por çierto mandado a vos, los homes buenos de la dicha / çiudat de Cuenqua; et que dentro de los dichos diez días, non vos sea fecha guerra, mal nin danno por nos nin por nuestro consejo nin por mandado del rey nin otro senyor nin poderoso nin mayor de la dicha çiudat nin de sus términos, fasta passados los dichos diez días; antes queremos que los dichos diez días sean / seguros e de tregua tornadiza porque vos podades ponervos en salvo, a vos e a todo lo vuestro.

(Calderón) Item queremos et otorgamos que si, por aventura, alguno o algunos nuestros vezinos o moradores en la dicha çiudat o en sus términos, desde la dicha çiudat de Albarrazín nin de sus términos, fuese fecha guerra, mal $/^{9}$ nin danno, dentro en el dicho tienpo a la dicha ciudat de Cuenqua nin a sus términos nin a cosa de lo vuestro, que sabido aquello por buena verdat, que los tales malfechores, si presos pudieren seyr, que sean muertos por traydores et de los sus bienes que sean satisfechos los injuriados. Et, si presos non pudieren seer, / que sean encartados de la dicha çiudat de Albarrazín et de sus términos para todos tienpos por traydores, como quebrantadores de tregua de conçejo, et que de sus bienes sean satisfechos los injuriados. Et, si aquéll o aquéllos questo fizieren et en el caso cayeren non tovieren bienes, maguer sean encarta-/ dos, que nos, el dicho conçejo de la dicha çiudat de Albarrazín et los del nuestro término, seamos tenidos de fazer emienda de nuestros bienes a los injuriados.

Otrosí, si por aventura acaesçiere durante la tregua que algunos almogávares de otras partes del regno de Aragón fizieren mal o danno en la $/^{12}$ dicha çiudat de Cuenqua o en sus términos et con el robo que fizieren sallieren o acaesçieren por la dicha çiudat de Albarrazín o por sus términos, et seyendo dellos sabidores, que seamos tenidos a los prender si pudiéremos averlos, et fazer justicia dellos, et les tomar todo lo que levaren robado para lo dar e tornar a cuyo fuere. Et si lo así non cunpliéremos et por nuestra mengua se fueren sabida buena verdat, que seamos tenidos de fazer emienda de nuestros bienes et de los del nuestro término a los injuriados.

Et todas estas cosas, segunt que aquí son scriptas, prometemos tener et conplir e fazer / tener e conplir nos, los offiçiales, conçejo e homes buenos de la dicha çiudat de Albarrazín, segunt que scriptas son en buena fe sin mal engannyo, so pena de trayçión.

Et, en testimonio de aquestas cosas, mandamos seyr fecha esta pú- 
blica carta signada de mano de Thomás Ferrández del Villar, nuestro scribano $/^{15}$ annyal et tenniet nuestro seyello, et seynllada con el seynllo pendient de nos, el dicho conçejo.

Facta carta en la dicha çiudat de Albarrazín, a XXIII días del mes de abril, anno a Nativitatis Dommini millesimo CCC $^{\circ}$ sexagesimo septimo.

Presentes testimonios fueron a las sobredichas cosas en el dicho conçejo: Garçi Pérez / de Riglós, Gill Pérez de Valvelidiello, Per Alfonsso et Ferrant Yuez de Monterdemenor de Días, vezinos de la dicha çiudat de Albarrazín.

Et yo, Tomás Ferrández del Villar, notario público et scribano annal en la çiudat de Santa María de Albarrazín, que a todas las sobredichas cossas con los dichos testimonios presente fui, et esta carta scrivir fiz et con mi sig-(signo)-no acostunbrado çerré et con el seyello pendiente del dicho conçejo seyellé. 

1373, diciembre 20. Albarracín.

Carta de tregua concedida al concejo de Cuenca por el de Albarracín. A.- A.M.C. Leg.3, Exp.12. Perg. de $415 \times 455 \mathrm{~mm}$. Plica de $22 \mathrm{~mm}$. con dos orificios en aposición horizontal y restos de cinta de lino en varios colores de donde pendería el sello, hoy perdido. Letra gótica cursiva aragonesa; tinta ocre claro; buena conservación.

Notas de Archivo al dorso: Letra coetánea: "Albarracín". Letra del s. XV: "Anno 1379". "L”. Letra del s.XVI: "Número 43" (tachado)- Letra del s. XVIII: "Tregua que otorgó a Cuenca la ciudad de Albarracín en 20 de diciembre hasta mayo de 1374. Copiado al folio 117". "Número 50".

B.- Copiado en el Libro de Vaqueta, ff. 117r-119r.( A.M.C. Leg.17, Exp.1)

CIT.: J.M. SÁNCHEZ BENITO, Las tierras de Cuenca y Huete..., pp. $25,172,187,188$.

En el nombre de nuestro Sennyor Dios. Amen.

Sepan todos quantos esta carta de tregua et segurança vieren como nos, el conçejo, officiales, cavalleros, escuderos et homes buenos de la çiudat de Sancta María de Albarrazín et de sus aldeas, conçejo en común / plegado et clamado a boz de pregón en I a plaça de la dicha çiudat segunt ques acostunbrado, todos concordes e bien abenidos a una voluntat et alguno nin algunos non contradicientes, queriendo guardar servicio de Dios et de los senyores reyes et paz et concordia entre christianos, sennalladamente entre aquellos que antigament ovieron con nos buena amigança et buena hermandat, segunt que de aquesto tenemos cartas complidament ante de agora fechas et otorgadas, et por evitar los males passados et que los buenos ${ }^{3}$ bivan en paz et en son siego et los malos ayan justicia et escarmiento, por aquesto, atreviéndonos a la merçet del nuestro sennyor el rey, atorgamos et reconosçemos que damos tregua buena, salva et segura et verdadera, de dicho et de fecho et de consejo, I a vos, el conçejo, officiales, cavalleros et escuderos et homnes buenos de la çiudat de Cuenqua et a los vezinos et moradores en la dicha çiudat et en sus términos et a todos en general et a cada uno por sí en especial:

Primerament que por nos, el dicho conçejo, / offiçiales, cavalleros, escuderos et homnes buenos de la dicha çiudat de Albarrazín nin por los vezinos nin moradores en la dicha çiudat nin en sus términos que serán de la nuestra jurisdicción, non sea fecha guerra, mal, nin dannyo alguno / a vos, el dicho Conçejo $/{ }^{6}$ et offiçiales, cavalleros et escuderos et homnes buenos de la dicha çiudat de Cuenqua ni a los vezinos nin moradores de la dicha çiudat ni en sus términos ni a cosa alguna de lo vuestro, de dicho ni de fecho nin de consejo durant la dicha/tregua, nin consintremos que vos sea fecha guerra nin mal nin dannyo a vos ni a 
cosa de lo vuestro; et, si por aventura, en este dicho tienpo et durant la dicha tregua acaesciere que por mandado de nuestro sennyor el rey o de otro sennyor, o de otro mayor o más poderoso que nos / aviésemos mandamiento o nos forçasen que ficiésemos guerra contra vos, o quel dicho sennyor rey o otro mayor et más poderoso que nos quisiese facer guerra desde esta ciudat de Albarrazín o de sus 19 términos o de aquellos lugares que están a nuestra jurisdicción, que escusar non lo pudiésemos, contra la dicha çiudat de Cuenqua o contra sus términos que son díus jurisdicción suya o contra alguna cosa de lo suyo, que nos, veynte días ante desque / sabidores fuéremos dello, seamos tenidos de facerlo saber por carta nuestra o por cierto mandado a vos, el dicho conçejo e homnes buenos de la dicha ciudat de Cuenqua, et que dentro de los dichos veynte días que non vos sea fecha / guerra, mal, nin dannyo, por nos ni por nuestro consejo nin por mandado del sennyor rey nin de otro sennyor, nin poderoso nin mayor de la dicha çiudat nin de sus términos fasta passados los di chos veynte días, ante queremos que los $/^{12}$ dichos veynte días sean seguros e de tregua tornadiça, por tal que vos podades poner en salvo a vos et a todo lo vuestro.

Otrosí, queremos et atorgamos que si, por aventura, por alguno o algunos vezinos nuestros o moradores aquí, en la dicha / çiudat de Albarracín o en sus términos que están a nuestra jurisdicción, desde la dicha çiudat o de sus términos, fuere fecha guerra, mal o dannyo durant la dicha tregua / a la dicha çiudat de Cuenqua / o a sus términos de su juridicción o a cosa de lo vuestro, que sabido aquello por buena verdat, que los tales malfechores, si presos pudieren seyr, que sean muertos por justicia como quebrantadores de tregua et que de los sus bienes sea fecha emienda et satisfación a los querellosos et $/ 15$ injuriados, et, si presos non pudieren seyr, que sean encartados de la dicha ciudat de Albarrazín et de sus términos para en todos tienpos como quebrantadores de tregua et de verdat puesta por concejo, et que de sus bienes sean satisfechos / los injuriados, et si aquell o aquellos que esto ficieren et en el caso cayeren non tovieren bienes, maguer sean encartados, que nos, el dicho concejo de la dicha çiudat de Albarrazín et los del nuestro término seamos tenidos et obligados de / façer emienda de nuestro bienes a los injuriados. Et si, / por ventura, acaeçiere que algunos almogávares de otras partes ficieren mal et dannyo en la dicha çiudat de Cuenqua o en sus términos et con el robo o furto que fiçieren, $/^{18}$ en salliendo dende, aportaren o acaeçieren por la dicha çiudat de Albarrazín o por sus términos de los lugares que son a nuestra jurisdicción, seyendo dello sabidores et requeridos por los que siguieren el rastro o el apellido que seamos / tenidos a seguir el apellido et prender aquellos, si pudiéremos haverlos, et facer justicia dellos, et tomarles todo lo que levaren robado o furtado para dar et tornarlo a cuyo fuere. Et si asín non lo compliremos o fiçiéremos et / por nuestra culpa o mengua se fueren por los non prender o embargar, que seamos tenidos de façer emienda de nuestros bienes, de nos, el dicho conçejo et común et de los del nuestro térmi- 
no, a los injuriados, pero que todavia en este caso sea $p^{21}$ sabida buena verdat en razón de la culpa.

Otrosí, porque algunos homes malos de los que se han fasta aquí entremetido de mal facer non ayan lugar de perseverar en sus malas obras nin en mal façer, queremos et ordenamos, / por quitar toda dubda et encubierta, que alguno ni algunos de aquellos que son enfamados de los dichos malefiçios que non puedan andar ni entrar en la dicha çiudat de Cuenqua ni en sus términos durante la dicha tregua , / salvo si fuere fama pública ques tornado a buena parte et obrare por ello o fuere con cartas nuestras de nos, el dicho conçejo, o de don Fernant López de Heredia, capitán en la dicha çiudat et en su término por el sennyor rey ${ }^{24}$ o en otra cualquiere manera, a librar de su facienda con uno o con dos o más conpannyeros, otros que fueren de buen titol et de buena fa ma a la dicha çiudat de Cuenqua - a otro lugar qualquiere de los sus términos de su / juridicción, et que vayan et vengan por los caminos derechos et poblados et non por sendas nin por lugares sospechosos, nin de noche, sinon de día, et en el primer lugar poblado que legaren del vuestro término que muestren et digan la / mandadería que lievan o la cosa sobre que van, porque claramente se entienda que andan con bien, et los que de otra guissa fueren fa llados en los vuestros términos durante la dicha tregua que los podades matar por justicia o como pudiéredes, ${ }^{27}$ et esto porque non se puedan encobrir los malos nin dezir que van a otras partes por reffoyr de la muerte et por escusar de las malas obras en que andan, mas que por el su peccado sean conprehendidos.

Et todas estas cosas / que aquí sos scriptas et cada una dellas prometemos tener et complir et facer complir et tener nos, el dicho conçejo et común, officiales, cavalleros, escuderos et homes buenos de la dicha ciudat de Albarrazín, segunt que en esta carta scriptas / son, so pena de trayción, fasta por todo el mes de mayo primero vinient que será del anno a Nativitate Domini,_millessimo CCC septuagesimo quarto, et ençima de todo aquesto de veynte días más de tregua tornadiça.

Et, $/{ }^{30}$ durant el dicho tiempo de la dicha tregua, que los vezinos et moradores de la dicha çiudat de Cuenqua et de los lugares de su término que son de su juridicción, que vayan et vengan con sus mercaderías o lo que menester ovieren aquí, a la çiudat / de Sancta María de Albarrazín et a los lugares de su término que son de la nuestra juridiccion, salvos et seguros, et que paguen lo s dercchos del sennnyor rey et los que perteneçen a nos, el dicho concejo et offiçiales, cavalleros, escuderos et homes / buenos de la dicha çiudat de Albarrazín, segunt que son acostumbrados, pero que non puedan sacar nirguna cosa de las que son vedadas para de fuera del regno de nuestro sennyor el rey, salvo que si algunos ganados mayores o menores ${ }^{33}$ de vezinos de la dicha çiudat de Cuenqua o de los lugares de su término que son de su juridicción entraren a pasçer las yervas et bever las aguas a la nuestra sierra et a los nuestros términos pagando los derechos del sennyor rey et los 
nuestros, / que anden salvos et seguros et que los puedan sacar et levar los dichos ganados así como los pusieron durant el dicho tiempo de la dicha tregua, sin pena et sin calonia alguna.

Et porque esto et todas las otras cosas sean guar-/ dadas, a mayor firmeça et por mayor abundamiento, nos, el dicho conçejo, offiçiales, cavalleros et escuderos et homes buenos de la dicha çiudat de Albarrazín et común de las dichas aldeas, concejalment damos poder et mandamos nos, $p^{36}$ el dicho concejo et común, a Martín Lóppez de Sancta María et a Pero Goncálvez de Noguera, nuestros vezinos, asín como nuestros síndicos et procuradores, que son presentes, por el poder especial que de nos tienen, que en ánimas de nos, dicho concejo et común, / juren e fagan juramento sobre el sennyal de la Cruz et de las palavras de los sanctos evangelios, por sus manos corporalment tenidos en nuestro nombre con sus manos, que cumpliremos et ternemos et guardaremos et faremos tener / et complir et guardar todas las sobredichas cosas en esta carta contenidas segunt que scriptas son.

Et nos, dichos Martín López de Sancta María et Pero Gonçálv ez de Noguera, asín como síndicos et procuradores, por el poder a nos dado por el dicho concejo et $/ 39$ común, cavalleros, escuderos et homes buenos de la dicha çiudat, en sus ánimas de aquellos, juramos a Dios et a Sancta María et a la Cruz et a los sanctos quatro evangelios de Dios, con nuestras manos corporalment tanidos, que el dicho concejo, offiçiales, cavalleros, / escuderos et homes buenos de la dicha ciudat de Albarrazín et comunidat de las aldeas de aquella que ternán, complirán et guardarán et farán tener et complir et guardar todas et cada unas cosas sobredichas segunt que en esta carta scriptas et contenidas son /.

Et desto mandamos nos, el dicho concejo et común, cavalleros, escuderos et homes buenos de la dicha çiudat de Albarrazín, facer esta carta en pergamino et seellada con el siello pendient del dicho concejo, et firmada et signada del notario de suso $/ 42$ scripto que present es en el dicho concejo.

Fecha en la dicha ciudat de Albarrazín, veynte días del mes de deziembre, anno a Nativitate Domini M CCC $L X X$ terçio.

Presentes testimonios fueron desto: Matheo [ Ximénez de Vaguena ] ${ }^{a}$ e Felip Díaz / de Mohort et Alvar Ferrández de Torres et Sancho Pérez de Tramacastiella, vezinos de la dicha çiudat.

Et yo, Johán Soriano, notario público en la ciudat de Sancta María de Albarrazín, qui a todas las sobredichas cosas con los dichos testimonios / ensemble present fuy en el dicho conçejo, et por mandado del dicho concejo esta carta de tregua et hermandat en forma pública de mi propia mano scriví et redux et con mi sig- (signo) -no acostumbrado cerré.

(a) Borroso en el original, así en el Libro de Vaqueta. 
1380, junio 30. Albarracín.

Carta de poder del concejo de Albarracín, nombrando procuradores para tratar con el de Cuenca sobre la situación del límite de la frontera que los separa..

A.- A.M.C. Leg. 113, Exp. 2. Papel de $385 \times 285$ mm. Letra gótica cursiva aragonesa; tinta ocre clara; regular conservación.

Notas de Archivo al dorso: Letra coetánea: "Carta de procuraçión de Alvarrazín para los junteros sobre la vega Tajo". Al Margen izquierdo, del s. XVI: "2".

CIT.: J.M. SÁNCHEZ BENITO, Las tierras de Cuenca y Huete..., pp. $25,172$.

Anno a Nativitate Domini millesimo CCC $L X X X$, día viernes, que se contava XXX días andados del mes de junyo, en la ciudat de Santa / María de Albarrazín. Concejo clamado et plegado en el cobertizo de la plaça de la dicha ciudat por mandado del

honrado Gil / Ximénez de Torres / lugartenient de judez por el honrrado Francisco Sánchez Mocara, judez enyal en la dicha ciudat

por boz ${ }^{3}$ de Johán de Frías, corredor público de la dicha ciudat, segunt que es acostumbrado. Do heran presentes en el dicho concejo, el dicho / tenient lugar de judez, Felipe Díaz de Mohort, mayordomo, Tomás Fernández del Villar, Lope Pérez de Torres regidores, Jo- /hán Pérez de Riglós, Pero Sánchez de Monterde, Fenant Pérez, guchillero, et Pero Martínez de Juvera, et des ha otros muchos homes $/{ }^{6}$ buenos, los quales al dicho concejo venir quisieron, todos concordes et bien abenidos et alguno nin algunos non contradijien -/tes, et semblantment Martín Lóppez de Santa María, por el senyor rey bayle de la dicha ciudat, por parte del dicho sennor / rey fazemos, establecemos et hordenamos ciertos, buenos et leales procuradores nuestros, de nos, dicho concejo, a vos honrados $/{ }^{9}$ Francisco Sánchez Moçara, judez de la dicha ciudat, absente así como si fuésedes presente, et a vos, Ferrant Pérez de To-/ yhuela, ciudadano de la dicha ciudat, presente. Et la dicha procuración recibient a amos a dos ensenble, specialment para que / por nos et en nonbre del dicho concejo, vayades personalment a los términos nuestros clamados la vega de Tajo et como afru- $/{ }^{12}$ enta con término de la ciudad de Cuenqua, a saber, en el Osejón, camino de Huélamo, dallá de la cannyada del Cubiello, tnuestro término, / et en la sennyoría del dicho sennyor rey de Aragón, como las aguas vierten del dicho Osejón a la parte de aquí, que es nuestro tér-/ mino, et afruenta de la parte de allá con término de la dicha ciudat de Cuenqua, non contrastant que la dicha ciudat de Cuenqua $/^{15}$ lo clame et diga seyer suyo fastal río de la dicha vega de Tajo. Et vos veyades con los yunteros et procuradores que la / dicha ciudat de Cuenqua deve enbiar a los dichos téminos, et por tirar scándalos, periglos et 
dannyos, ensanble / los dichos yunteros et procuradores podades sennyalar et poner mojones en el dicho término del dicho Osejon, et como va por a- $/$ ${ }^{18}$ quella derecha que las aguas vierten fastal dicho río de la vega de Tajo, lo qual es nuestro, et los de la dicha cib-/ dat de Cuenqua afirman et claman suyo et fazen comunero et entredicho en esta manera: Que los de la dicha ciudat de Cuenqua / et qie ellos querrán et nos, et qui nos querremos, podamos et puedan pacer et adentrar con sus ganados grosos et me-/ ${ }^{21}$ nudos, et tajar en aquellos que por vos et por ellos sea así mojonado et senyalando, foreos, franquos et líberos / de todas prendas montadgo ervagen et que por la nuestra parte non les sea tomado, mas que anden et puedan andar en a-/ quello franquos et seguros segunt dicho es. Empero con tal procuración, que por el esmojonamiento et sennyalamiento que por ${ }^{24}$ vos et por los dichos yunteros et procuradores de la dicha ciudat de Cuenqua será fecho en el dicho término entredicho; (... / ...) pueda allegar alguna de las partes posesión nin pueda seyer perjudicio de alguna dellas, ante que cada una de las dichas / partes finque salvo su derecho que lo aya et lo pueda aver por yuntas o en otra manera en su tienpo et lugar cada que decla- $/ 27$ rado será entre las dichas ciudades de quáles deven seyer et fasta do ser alguna contrariedat. Et todo lo que por / vos en las sobredichas cosas con los dichos procuradores de la dicha ciudat de Cuenqua será fecho, nos lo avemos e avremos / por firme et durable para agora et para todos tienpos et contra ello non vernemos en algún tienpo por alguna manera.

Et $/ 30$ desto vos mandamos fazer aquesta carta pública de poder, signada por Johán Pérez de Toyhuela, notario público por actoridat re-/ al, qui a esto presente fue.

Fecha día, annyo, lugar et mes de suso contenidos.

Presentes testimonios fuero: Martín / Pérez de Torres et Miguel Sánchez de Noguera, vezinos de la dicha ciudat de Albarrazín.

Et yo, Johán Pérez de Toyhuela, ${ }^{33}$ notario público por actoridat real por toda la tierra et sennyoría del sennyor rey de Aragón, qui a las sobredichas / cosas present fui et por mandado del dicho concejo de Albarrazín este poder scriví, et con el mi sig-(signo) -no acostunbrado çerré. 
1380, julio 2. Entre los términos de Albarracín y Cuenca.

Convenio entre los procuradores de los concejos de Albarracín y Cuenca para que los ganados de ambos concejos puedan pastar en un terreno fronterizo sin ser molestados.

A.- A.M.C. Leg. 113, Exp. 3. Papel de $320 \times 290$ mm. Letra gótica cursiva aragonesa; tinta ocre claro; mala conservación, además de faltarle un fragmento al final.

Notas de Archivo: Al margen izquierdo, del s.XVI: " 3 ".

CIT.: J.M. SÁNCHEZ BENITO, Las tierras de Cuenca y Huete..., p.25.

Llunes, dos días andados del mes de julio, era de mill quatroçientos et dizeocho annyos, que senblantment se intitulava anno a Nativitate Domini I millessimo CCC ottuagesimo.

En presencia de los notarios públicos et de los testigos dius criptos conparecieron en el lugar dius scripto los honrrados / Johán Álvarez de Leza et Gonçalvo García de Viana, con Martín Lóppez de Lorbes, notario, por parte de la ciudat de Cuenqua, asín como yunteros et pro- ${ }^{3}$ curadores de aquella segunt se contiene por carta de procuración que mostraron de la dicha ciudat de Cuenqua, la qual fue fecha a XXV días de ju-/ nnyo de la dicha hera et signada del signo de Pero Fernández de Torreziella, scrivano público de la dicha ciudat de Cuenqua. Et senblantment de la / otra parte conparecieron en el dicho lugar los honrrados Francisco Sánchez Mocara, judez de la dicha ciudat de Albarrazin, et Ferrant Pérez de Toyhuela, procura- ${ }^{6}$ dores et mandaderos de la dicha ciudat de Albarrazín, et mostraron el poder que avían de la dicha ciudat fecho por Johán Pérez de Toyhuela, notario público por ac-/ toridat real, a XXIX días del dicho mes de junnyo del dicho annyo. Los quales dichos poderes fueron dados et apoderados, a saber: Es el poder de la dicha / cibdat de Cuenqua al dicho Johán Pérez, notario, et el de la dicha ciudat de Albarrazín al dicho Martín Lóppez, scrivano. Con los quales dichos poderes los $1^{9}$ dichos procuradores et yunteros retovieron su acuerdo para declarar sobrello a servicio los sennyores reyes et a provecho común de las dichas / ciudades.

Et después de aquesto, en este dicho día mismo et lugar, los dichos procuradores et yunteros declararon en este fecho lo que se sigue: / (...) los dichos Johán Álvarez de Leza et Gonçalvo Garcia de Viana et Martín López de Lorbes, scrivano, por parte del concejo, cavalleros, escu-112 deros et oficiales et homes buenos de la dicha ciudat de Cuenqua, et nos, los dichos Francisco Sánchez Moçara, judez, et Ferrant Pérez de To-/ yhuela, por parte del Concejo et oficiales et homes buenos de la dicha ciudat 
de Santa María de Albarrazín, vistos et bien diligentment / examinados los dichos poderes de cada una de nos, las dichas partes, que a nos dado fue por cada una dellas, querientes los servicios ${ }^{15}$ de los senyores reyes, así de Castiella como de Aragón, et el bien et provecho de las dichas ciudades Cuenqua et Albarrazín et de los ha vitantes en / ellas et en sus términos, por tirar grandes questiones que fasta al día de oy se han recreçido entre las dichas ciudades e sus términos, o se espera-/ van recrecer, sobre los términos entredichos que son del río de la vega de Tajo fata la canyada del Cubiello, et de la canyada del Cubiello / ${ }^{18}$ fastal dicho río de la vega de Tajo, lo cual la dicha cibdat e Cuenqua afirrma seyer suyo et del sennyorío del rey de Castiella et esso mes-/ mo afirman 1os de la dicha ciudat de Albarrazín seyer suyo et del sennyorío del rey de Aragón. Por ende, por el poder a cada uno de nos dado por / las dichas ciudades, non entendiendo en algua cosa perjudicar a alguna de las dichas ciudades el su derecho, ante aquello fincando salvo que las ${ }^{21}$ dichas ciudades se lo puedan demandar la determinación et dec1aración de los dichos términos cuyos son o a qui pertenece la propiedat et el sennyorío de aquel-/ 1 os et por do et como se deven partir en la mercet de los dicchos sennyores reyes. Entretanto, por escusar los dichos periglos et males, prendas et re-/ prendas et dannyos que se podrían seguir entre las dichas ciudades et sus términos, et por reformar los buenos debdos que sienpre los abitantes en las dichas ${ }^{24}$ [ ciudades los ] ovieron en uno fata aquí et esperan mayorment aver daquí adelalant sobre esto, en guarda de las sobredichas cosas, por traer a efecto de bien / (...) [ con ]-cordia que prerdas nin reprerdas en el di cho espacio dubdoso non sean fechas por los cavalleros amontaraçes que gauardan los términos de las / dichas ciudades, por nonbre de aquellas o por cada una dellas, assentamos parte et abenencia por los dichos poderes en esta manera: Desde oy adelant , / ${ }^{27}$ algún caval1ero ni montaraz que los términos de las dichas ciudaces guardaran, non prenden nin monten en el dicho espacio o pacil dubdoso (...) / taron que la dicha declaración espera seyer fecha, cúyos son los dichos términos o a quién perteneçe, por los dichos conçejos en la merçet de los dichos sennores / reyes, ante en los sobredichos nonbres ponemos et asentamos que en este espacio et pacil dubdoso puedan andar los ganados mayores et me- - $^{30}$ nores, assín del regno et sennyorío de Castiella como del regno et sennyorío de Aragón, paciendo las yervas et beviendo las aguas, sin monta et sin / pena et sin calonnya alguna, lo qual damos comunero fasta que la questión sea declarada, según dicho es. Et si, por aventura, en el dicho pacil o espa-/ çio algunos de los dichos cavalleros o montaraçes, ante de la dicha dec1aración prendaren o montaren algunos ganados de los que y entraren a pacer las yer $-f^{33}$ vas et bever las aguas, que sean tenudas las dichas çiudades de mandar a sus cavalleros de la sierra o montaraçes que lo tornen todo lo que toma-/ ren a sus duennyos con las costas et misiones que sobrello les recreciere. Empero, como quier que sobre este fecho nos, los dichos yunteros et procuradores, / según los poderes a nos dados, 
avemos asentado estos fechos sequnt nuestra entención, dexamos la mejoría et correçión a las dichas ciudades de Cuenqua et de Al-/36 barrazín et a los buenos dellas, que mejoren lo que su mercet fuere et por bien tovieren.

Et sobre esto, mandamos a los dichos notarios presentes que fagan I dello dos cartas públicas, amas de un tenor, para cada una de las dichas çibdades la suya, et las signen de sus signos.

Fecha en el espaçio o pa-/ cil entredicho, dos días de julio, ut supra.

Testigos que estavan a esto presentes: Pero Sánchez, fijo de Andrés Martínez de Valsalobre, vezino de Tragacete, $/^{39}$ et Domingo Motos, vezino de Huélamo, et Pero Gonçálvez, vezino de Frías, et Pero Martín de Guadalaviar, vezino de Villar del Tovo, alde-/ as de la dicha cibdat de Albarrazín.

Et yo, Martín López de Lorbes, escrivano público en la dicha cibdat de Cuenca, fuj a todo esto presente en un con $\mathrm{C} . ..)^{\mathrm{a}}$

(a) A partir de aquí falta el original. 


.


1392, mayo 18. Albarracín.

Carta abierta del concejo de Albarracín reclamando al de Cuenca la devolución de 122 cabezas de ganado requisadas por los caballeros de la sierra a uno de sus vecinos.

A.- A.M.C. Leg. 113, Exp. 4. Papel de $195 \times 290 \mathrm{~mm}$. Restos del sello de placa al dorso de $55 \mathrm{~mm}$. de diámetro. Letra gótica semicursiva aragonesa: tinta ocre; mala conservación.

Notas de cancillería municipal: Al dorso: "Registrada" (?). Notas de Archivo: En la parte superior izquierda, del s.XVI: "4".

CIT.: J.M. SÁNCHEZ BENITO, Las tierras de Cuenca y Huete..., pp. $25,172$.

A los honrrados el concejo, cavalleros, escuderos, oficiales et homes buenos de la ciudat de Cuenqua. Nos, el concejo, ofi-/ciales et homes buenos de la ciudat de Sancta María de Albarrazín, vos embiamos mucho a saludar de la salut et honra que para nos / querríamos.

Fazémosvos saber que avemos entendido que agora el domingo más cerqua passado, andando el ganado de Domingo Ximeno, $/ 3$ vezino de Calomarde, aldea nuestra, en la canyada el Cubiello, entredicho qui es et comunero para pacer los vuestros ganados et los nuestros por / sentençia et composición fecha entre vos et nos, vinieron los cavalleros de la sierra de essa ciudat et leváronsse del ganado del dicho Domin-/ go Ximeno $\mathrm{C} X$ $X$ II cabeças de ovejas et carneros, la qual cosa dius, devida honor, non fue bien fecha ni avían razón de levar reses del $/ 6$ dicho entredicho, et do en ca so que en la sierra vuestra las tomasen, lo que dizen que no fizieron, no avían razón de levar tanto ganado. Et el dicho / Domingo Ximeno C...) ${ }^{\text {a }}$ lugar et entredicho dizen que se aduxo por [emienda ] C XX borregos, la qual cosa nos fizo grant desplazer porque sin nuestro consejo lanzo (?) assi, que por otra forma de justiçia solemos librar $/^{9}$ entre vos et nos semblantes fechos. Por la qual razón han foydo los ganados de la sierra dessa parte et desta, et esto no va bien / entre buenas hermandades, ya sea ponemos más culpa en nuestro vezino, por quanto primero (?) non fuestes reque ridos por nos de la justicia. Por que vos rogamos que tengades por bien de aver verdadera información et, si los dichos cavalleros de la sierra tomaren el dicho ganado en el $/ 12$ dicho entredicho, do aquesta parte afirman que lo tomaron, que lo fagades luego tornar al dicho nuestro vezino como los dichos borregos estén / por nos embargados, et luego [ de present ] los faremos tornar a daglos de quien son, con aquesto escusaredes otras pendras y rependras / que por la dicha razón se podrían seguir et aún otros danyos et periglos, et non sería conservada la buena hermandat et amigança que ha seydo $/{ }^{15}$ antigamente et es entre vos et nos. 
Et desto vos embiamos esta nuestra carta abierta et seyellada con nuestro seyello.

Scripta en la dicha / ciudat de Albarrazín, a XVIII días de mayo, anno a Nativitate Domini, millesimo CCC nonagesimo secundo.

(a) Coincide con el doblez del papel y está roto, faltando prácticamente el renglón completo. 
1413, abril 6. Albarracín.

El concejo de Albarracín solicita del conquense que nombre procuradores para resolver, junto con los nombrados por él, los contenciosos pendientes entre ellos.

A.- A.M.C. Leg. 834, Exp. 8. Papel de $250 \times 230$.

Letra gótica cursiva aragonesa; tinta ocre claro; mala conservación. Notas de cancillería municipal: Letra coetánea: "Allos muyt honorables el concejo, cavalleros, escuderos, regidores e omnes de la ciudat de Cuenqua". Notas de Archivo: Letra coetánea castellana: "La çibdad de Albarrazín. Carta mensagería". Letra del s. XVI: "(Cru) Carta misiba de Albarracín. Anno 1413".

Muyt honorables concejo, cavaleros, escuderos, oficiales, regidores et homes buenos de la ciudat de Cuenqua. Nos, el concejo, ofi-/ ciales, regidores et omnes buenos de la ciudat de Santa María de Albarrazín, salut et aparellada voluntat a vuestros plazeres.

Bien / creyemos que se vos deve recordar de algunas quistiones et debates que son entre vos et nos et vezinos vuestros et nuestros et otros so- $\beta$ bre prendas et reprendas fechas en los annyos et tienpos pasados, las quales penyoras et repenyoras son cessadas de non ve-/ nyr a justo conoscimiento entre vos et nos por razón de 1os vedamientos, si quier sobreseymientos fechos a vos et a nos / por los sennyores reyes de Aragón et Castiella, et no resmeos por razón de las grandes opresiones en esti regno de Aragón $/{ }^{6}$ venidas por no aver rey conoscido, et como lado Dios ayamos [ rey ] verdadero et conoscido, el qual es mucho tenido guar-/ dar esi regno et aquesti en paz y en justicia, et esi concejo (...) [orde-] nar et guardar 1os buenos deudos et amoríos que / son entre los dichos senyores, et entre vos et nos buena hermandat et (...) antiga si avemos consideado en nos que por servar ${ }^{\beta}$ los dichos buenos deudos que todas et qualesquiere quistiones (...) [ entre ] vos et nos, et vezinos vuestros et nuestros devan seyer deter-/ minadas por justicia, beramente (?) et sin dannyos et misiones et no por via de penyoras et repenyoras, por tirar todo / greuge et escándalo et misiones superfluas si a vos, esi concejo, bien visto es. Por aquesto, con aquella africión que mejor po-/12 demos, con los presentes vos pregamos et en subsidio de justicia requereímos que pora conoscer et determinar todos et quales quiere / greuges contra aquesa ciudat et aquesta et vecinos vuestros et nuestros, querades et devades sacar et esleyr vuestros junteros et prccurado-/ res con poderes conplidos segunt que otros de vosotros avemos acostunbrado en senblares negocios, et querades asignar día et tienpo $/ 15$ adaquesto como esi concejo sea presto et perellado conplir las sobredichas cosas por todo su poder segunt 
dicho es. Et / nos, esti concejo, asín vos lo rogamos et en debdo de justicia requerimos, plaziendo a vos, que las sobredichas cosas quera-/ des poner con efecto en obra et aver vos emos mucho que guardar.

El Santo Espiritu sea en vuestra guarda et de lo que aver- $/^{18}$ des enbier ayamos vuestra respuesta. Scripta en la ciudat de Alvarracín, a VI de abril, anno CCCC XIII. 